\title{
Comunicação do Banco Central, Expectativas de Inflação e Profecia Autorrealizável: Evidências para o Brasil
}

\section{Central Bank Communication, Inflation Expectations and Self- Fulfilling Prophecy: Evidences for Brazil}

\author{
Gabriel Caldas Montes* \\ Rodolfo Tomás da Fonseca Nicolay**
}

\begin{abstract}
Resumo: Estudos sobre comunicação do Banco Central, em países emergentes, ainda são escassos. Não existe, para o caso brasileiro, estudo acerca da influência da comunicação sobre as expectativas de inflação e, consequentemente, sobre a inflação. Portanto, este trabalho analisa a influência da comunicação da autoridade monetária brasileira sobre as expectativas de inflação e sobre a inflação e verifica se os comunicados da autoridade monetária possuem um caráter de profecia autorrealizável. O estudo contribui com a literatura ao elaborar - utilizando a teoria dos conjuntos fuzzy - um novo índice de comunicação e ao identificar uma situação paradoxal denominada de "paradoxo da comunicação". Os resultados sugerem que a comunicação do Banco Central é capaz de apresentar um efeito adverso sobre as expectativas de inflação e sobre a própria inflação quando indica que há alto grau de perda de controle da inflação.
\end{abstract}

Palavras-chave: Comunicação. Expectativa de inflação. Banco Central. Política monetária. Profecia autorrealizável.

Abstract: Studies on Central Bank communication, in emerging countries, are still scarce. There are no studies for the Brazilian case about the influence of communication on inflation expectations and therefore on inflation. Therefore, this paper analyzes the influence of the communication of the Brazilian monetary authority on inflation expectations and on inflation and, thus, aims to verify whether such communicates of the monetary authority have a character of self-fulfilling prophecy. The study contributes to the literature since it develops - using the theory of fuzzy sets - a new index of communication, and identifies a paradoxical situation here called the "paradox of communication". The results suggest that the central bank's communication is able to present an adverse effect on inflation expectations and on inflation itself when it states the possibility of losing control of inflation.

Keywords: Communication. Inflation expectation. Central Bank. Monetary policy. Selffulfilling prophecy.

JEL Classification: E31; E52; E58.

\footnotetext{
* $\quad$ Universidade Federal Fluminense, Departamento de Economia; Conselho Nacional de Pesquisa (CNPq).E-mail: gabrielmontesuff@yahoo.com.br

* * Universidade Cândido Mendes, Mestrado em Economia e Gestão Empresarial. E-mail: r-nicolay@ hotmail.com
} 


\section{1 lntrodução}

É possível observar ampla adoção do regime de metas para inflação no início da década de 1990, assim como um aumento na importância da transparência para o processo de formação das expectativas (GERAATS, 2002; MENDONÇA; SIMÃO FILHO, 2007). O reconhecimento de que agentes atuam de maneira forward-looking (ou seja, tomam decisões olhando pra frente, mas utilizando todas as informações relevantes disponíveis) faz da política monetária a arte de gerenciar as expectativas (WOODFORD, 2003). De acordo com Blinder et al. (2008), como fica cada vez mais evidente que o gerenciamento das expectativas é uma função importante da autoridade monetária, a comunicação do Banco Central ganha destaque como instrumento na tarefa de guiar as expectativas do público. Nesse sentido, o estudo da comunicação do Banco Central ganha cada vez mais evidência devido à sua importância para a condução da política monetária (ERHMANN; FRATZCHER, 2007a).

Os bancos centrais, sob o regime de metas para inflação, tornam público quatro aspectos relacionados à política monetária: a) os seus objetivos e estratégias; b) as razões por trás das decisões políticas; c) as perspectivas sobre o estado da economia; e d) as decisões futuras de política monetária. A literatura sobre comunicação do Banco Central concentra estudos a respeito dos comunicados acerca das decisões futuras de política monetária, de forma que poucos trabalhos utilizam conteúdos diferentes. Ou seja, na literatura sobre comunicação do Banco Central, existem ainda outros aspectos a serem explorados.

Quanto à influência da comunicação na economia, há duas abordagens principais: uma discute o impacto da comunicação do Banco Central nos mercados financeiros ${ }^{1} \mathrm{E}$ a outra lida com a influência da comunicação sobre o desempenho econômico. ${ }^{2}$

Na última década, diversos estudos sobre comunicação do Banco Central foram elaborados. Entretanto, as pesquisas se concentram em análises de países desenvolvidos. Por sua vez, esses estudos são em sua maioria voltados para a análise da influência que a comunicação exerce sobre as expectativas formadas nos mercados financeiros acerca do comportamento das taxas de juros e de câmbio (no curto e no longo prazo), como também sobre as expectativas formadas para o comportamento futuro da autoridade monetária. ${ }^{3}$

1 Por exemplo, Kohn e Sack (2004), Reeves e Sawicki (2007) e Ehrmann e Fratzscher (2007a, 2009).

$2 \quad$ Por exemplo, Fujiwara (2005), Rozkrut et al. (2007) e Ullrich (2008).

3 Por exemplo, Kohn e Sack (2004), Connolly e Kohler (2004), Musard-Gies (2006), Andersson, Dillén e Sellin (2006), Rosa e Verga (2007), Reeves e Sawicki (2007), Ehrmann e Fratzscher (2007a, 2009), Hayo e Neuenkirch (2010), Brand, Buncic e Turunen (2010), Hayo, Kutan e Neuenkirch (2010), Ranaldo e Rossi (2010), Sturm e Haan (2011), Rosa (2011) e Berger et al. (2011). 
No tocante às economias emergentes sob regime de metas para inflação, a análise acerca dos efeitos da comunicação sobre a economia é fundamental. Como apontam Mishkin e Savastano (2001), são maiores as incertezas sobre o controle da inflação nesses países e, portanto, maiores as dificuldades em orientar as expectativas.

Nesse sentido, quatro lacunas são identificadas: a) trabalhos sobre comunicação dos bancos centrais em países emergentes de destaque (como é o caso do Brasil) ${ }^{4}$ ainda são escassos; b) são poucos os trabalhos relacionados à influência da comunicação dos bancos centrais sobre o desempenho macroeconômico (como por exemplo, sobre inflação e expectativas de inflação); c) existem poucos trabalhos que utilizam o conteúdo dos comunicados referente ao estado da economia; e, d) até então, não existem, para o caso brasileiro, estudos acerca da influência da comunicação, por meio das atas do Comitê de Política Monetária (Copom), sobre as expectativas de inflação e, por conseguinte, sobre a própria inflação. Nesse sentido, o presente trabalho tem como objetivo analisar, para o caso brasileiro, a influência da comunicação do Banco Central acerca do estado da economia sobre as expectativas de inflação e, também, sobre a inflação observada. Ademais, busca-se verificar se os comunicados da autoridade monetária possuem um caráter de profecia autorrealizável.

O presente trabalho contribui com a literatura sobre a comunicação do Banco Central nos seguintes aspectos:

a) analisa a influência dos comunicados da autoridade monetária, por meio das atas do Copom, e, portanto, a influência que exerce a percepção da autoridade monetária no tocante ao comportamento da economia, sobre as expectativas de inflação e, também, sobre a inflação observada;

b) propõe de maneira inovadora, utilizando a teoria dos conjuntos fuzzy como método, um indicador que capta, com base nas informações disponibilizadas nas atas do Copom, a percepção da autoridade monetária em relação ao estado da economia, e em particular à estabilidade de preços;

c) aborda a ideia de profecia autorrealizável ao tratar da influência do conteúdo informacional presente nos comunicados da autoridade monetária sobre as expectativas de inflação e, portanto, sobre a taxa de inflação observada; e

d) sugere uma situação paradoxal denominada neste estudo de "paradoxo da comunicação".

No tocante ao paradoxo da comunicação, para um país que adotou o regime de metas para inflação, o desenvolvimento da transparência e das práticas de

4 Em relação à literatura sobre comunicação do Banco Central do Brasil, é possível destacar, por exemplo, os trabalhos de Filho e Rocha (2009, 2010), Mendonça e Faria (2010, 2011), Janot e Mota (2012) e Montes (2012). 
comunicação é essencial para a conquista de credibilidade do regime e, portanto, para a ancoragem das expectativas de inflação em relação à meta de inflação. Entretanto, uma situação paradoxal pode surgir: se por um lado a comunicação é importante para guiar as expectativas dos agentes e, assim, fortalecer a âncora nominal, proporcionando credibilidade ao regime e ao banco central, por outro o conteúdo das informações comunicadas pode atuar desestabilizando as expectativas e enfraquecendo a âncora nominal. Se, por exemplo, na ata do Copom é informado que a inflação está dando sinais de descontrole, essas informações podem ser incorporadas às expectativas formadas pelos agentes em relação à inflação, os quais passam a formar contratos na economia com base nessas expectativas. Dessa forma, aquilo que foi anunciado pela autoridade monetária, ao ser levado em consideração pelos agentes em suas expectativas, se torna uma "realidade" em termos de desempenho econômico. Ou seja, situações de profecias autorrealizáveis podem surgir dos comunicados da autoridade monetária e, assim, o paradoxo da comunicação se revelar quando informações pessimistas sobre o estado da economia contaminam expectativas e, por conseguinte, se tornam realidade, minando a credibilidade do regime e da autoridade monetária. Isso não significa que a autoridade monetária não deva revelar informações ruins sobre o estado da economia. Ou seja, o presente estudo não defende a opacidade; pelo contrário, a transparência é fundamental para o fortalecimento da democracia e para a confiança do público em relação ao Estado. Entretanto, as autoridades devem estar cientes que aquilo que revelam é incorporado às expectativas do público, e, portanto, devem agir de maneira comprometida com objetivos críveis previamente estabelecidos.

Além desta introdução, o artigo está dividido da seguinte maneira: a segunda seção aborda a importância da comunicação do banco central para o processo de formação das expectativas dos agentes e elabora uma breve resenha da literatura empírica sobre o tema, apontando os principais trabalhos elaborados na literatura internacional e aqueles elaborados para o caso brasileiro; na terceira seção são apresentadas as principais formas de mensurar a comunicação do banco central por meio de índices, e é elaborado um novo índice com base na teoria dos conjuntos fuzzy; na quarta seção é elaborada a análise empírica, com base no caso brasileiro, para a influência da comunicação do banco central sobre as expectativas de inflação e, por conseguinte, sobre a inflação; para finalizar, a quinta seção apresenta as considerações finais do trabalho. 


\section{Importância da Comunicação como Guia de Expectativas}

A comunicação do banco central é a provisão de informação para o público acerca da política monetária presente e futura, do ambiente econômico e dos objetivos do banco central. Essas informações auxiliam na formação de expectativas dos agentes quanto à condução da política monetária no futuro e à inflação para os períodos seguintes. Nesse sentido, os comunicados atuam de maneira útil ao reforçar a accountability necessária a um banco central independente, como também ao guiar as expectativas dos agentes (JANSEN, 2011).

A literatura que aborda a influência da política monetária sobre a economia sugere que para o banco central afetar as decisões dos agentes (e, portanto, o desempenho da economia) deve ser capaz de afetar as expectativas nos mercados financeiros em relação às taxas de juros de curto prazo (BLINDER et al., 2008). Nesse sentido, no regime de metas para inflação, a comunicação tem como finalidade atuar auxiliando a política monetária no processo de formação das expectativas relacionadas não somente às taxas de juros com diferentes maturidades, mas, também, na ancoragem das expectativas de inflação. Quando a comunicação consegue guiar essas expectativas, a política monetária tende a se tornar mais previsível atingindo seu objetivo de influenciar as decisões dos agentes. Logo, a comunicação é um meio importante para os bancos centrais influenciarem as expectativas dos agentes (GÜRKAYNAK; SACK; SWANSON, 2005).

Segundo Erhmann e Fratzcher (2007a), é consensual que a comunicação atue como um instrumento útil da autoridade monetária. Contudo, dentro da literatura sobre o tema, há divergências em relação ao nível ótimo de comunicação e ao conteúdo que deve ser comunicado, pois prover informação em excesso (ou insuficiente) para o mercado pode levar a interpretações equivocadas e, por outro lado, porque a questão não é somente uma opção de comunicar ou não comunicar, mas o que é comunicado. Ou seja, o conteúdo dos comunicados também afeta o processo de formação de expectativas e, portanto, o desempenho econômico.

\subsection{Evidências Empíricas sobre Comunicação do Banco Central}

A literatura empírica existente sobre comunicação da política monetária concentra grande parte dos seus esforços em mostrar a influência da comunicação do banco central sobre os movimentos na taxa de juros (GUTHRIE; WRIGHT, 2000; KOHN; SACK, 2004; ANDERSSON; DILLÉN; SELLIN, 2006; EHRMANN; FRATZCHER, 2007a, 2007b; ROSA; VERGA, 2007; HEINEMANN; ULLRICH, 2007; STURM; HAAN, 2011). 
Em relação aos mercados de ativos, Gürkaynak, Sack e Swanson (2005) analisam as comunicações do Federal Reserve (FED). O trabalho mostra que os comunicados do FED têm um grande impacto na taxa de juros de longo prazo, já que pode ser explicado pelo fato dos comunicados conterem informações sobre variáveis no futuro que divergem das projeções dos agentes. Ademais, os resultados levam a crer que o FED tem a capacidade de se comprometer com objetivos e movimentar os mercados na direção desejada.

Ainda em relação ao impacto da comunicação sobre mercados de ações, Rosa (2011) avalia o impacto dos comunicados do banco central por meio de um estudo de eventos com dados de alta frequência. Os resultados indicam que um aperto na política monetária resulta em uma queda nos mercados de ações. Ademais, somente a parcela não antecipada compreendida nos anúncios do FED movem os mercados.

Há, também, estudos sobre os efeitos da comunicação do banco central sobre as taxas de câmbio (JANSEN; HAAN, 2005, 2007a; COMRAD; LAMLA, 2007; FRATZSCHER, 2008). De um modo geral, as análises são feitas por meio de estudos de eventos e dados de alta frequência, e os trabalhos sugerem que a comunicação é eficaz em afetar o nível e a volatilidade das taxas de câmbio.

Os trabalhos sobre o efeito da comunicação sobre as expectativas de inflação são mais escassos na literatura. O trabalho de Jansen e Haan (2007b) analisa a relação entre as expectativas de inflação obtidas por meio de títulos indexados à inflação e os riscos para a estabilidade de preços (mensurada por meio da frequência da palavra "vigilante" nos comunicados do European Central Bank - ECB). O resultado encontrado indicou uma relação negativa, entretanto, pequena, entre os comunicados e as expectativas de inflação. Por sua vez, Ullrich (2008) analisa o impacto da comunicação do ECB, por intermédio do conteúdo da conferência 5 realizada após a divulgação da taxa de juros, sobre a formação de expectativa dos agentes. Os resultados sugerem que uma comunicação que indique um aperto monetário aumenta a expectativa de inflação para seis meses. Isso se deve pelo conteúdo sobre risco de inflação obtido no comunicado.

Em relação à literatura empírica sobre comunicação do banco central para o Brasil, ainda é escassa. Costa Filho e Rocha (2009) analisam a consistência da política monetária e a capacidade da comunicação explicar os movimentos na taxa básica de juros da economia. Com base na metodologia de Rosa e Verga (2007), constroem um índice que classifica os comunicados como: a) de aumento; b) de manutenção; ou c) de redução da taxa de juros. O sinal obtido indica que a comunicação move os mercados na direção correta e com significância. Ademais,

$5 \quad$ No ECB, após a reunião para determinação da política monetária, o presidente concede uma conferência na qual responde às perguntas referentes à decisão tomada. Essa conferência é equivalente à ata liberada pelo Banco Central do Brasil. 
a estimação de um modelo probit mostra que a comunicação é consistente em um percentual considerável. Outra análise realizada diz respeito à mensuração de uma regra de Taylor que incorpora o efeito da comunicação do banco central para a determinação da taxa de juros. Os resultados obtidos justificam a atenção despendida pelo mercado financeiro para o conteúdo informacional existente nos comunicados do Banco Central do Brasil.

Por sua vez, Costa Filho e Rocha (2010) buscam analisar se a comunicação do Banco Central do Brasil, a partir das atas do Copom, afeta o comportamento do mercado de juros futuro, observando se o comportamento dos agentes nos dias do comunicado difere dos demais dias. $\mathrm{O}$ trabalho buscou mostrar se há um entendimento da comunicação, reduzindo a assimetria de informação entre o banco central e os agentes, e reduzindo a volatilidade em variáveis financeiras. $\mathrm{O}$ trabalho analisa, também, se as respostas nos mercados financeiros seguem os propósitos dos comunicados. Os resultados indicam que, nos dias de divulgação das atas do Copom, a taxa de juros sofre um aumento. Também mostram que a divulgação da ata e do relatório de inflação possui um efeito estabilizador, reduzindo a volatilidade da taxa de juros.

O estudo de Mendonça e Faria (2010) analisa a influência da comunicação sobre os mercados financeiros. O trabalho busca observar o impacto da comunicação do banco central sobre as taxas de juros, a partir das taxas de juros negociadas no mercado futuro, utilizando as atas do Copom. A análise é dividida em quatro períodos: a) três dias antes da reunião; b) entre a reunião e a divulgação da ata; c) três dias após a divulgação da ata; e d) o período de purdah. A comunicação se mostra importante em todos os períodos, mas com maior intensidade nos dias que precedem a reunião.

O trabalho de Montes (2012) mostra a influência da comunicação sobre o spread e taxas de juros com diferentes prazos de maturidade. Os resultados indicam que os comunicados importam e os mercados respondem na direção correta. Os resultados ganham robustez com a estimação por três métodos - mínimos quadrados ordinários (OLS), método generalizado dos momentos (GMM) e vetor autorregressivo (VAR) -, os quais mostram a mesma influência da comunicação sobre os mercados.

A literatura empírica existente mostra resultados robustos para os efeitos da comunicação do banco central, e, em particular, dos comunicados sobre a taxa de juros. ${ }^{6}$ Contudo, as análises se concentram no conteúdo referente à política monetária futura. Trabalhos sobre a influência da comunicação sobre a inflação e as expectativas de inflação ainda são, de um modo geral, escassos na literatura e necessitam de atenção especial para seus resultados, pois o objetivo final do banco central é o controle da inflação e a ancoragem das expectativas. Ademais,

6 O Quadro 1, no Apêndice B, apresenta uma síntese dessa literatura. 
pelo fato de a linguagem dos comunicados não ser clara e o conteúdo usualmente utilizado na literatura sobre política monetária futura não ser o mais indicado para explicar a formação de expectativas dos agentes, uma vez que estes utilizam toda informação disponível, é necessária e justificada a criação de um novo índice que meça a percepção do banco central acerca do ambiente econômico e a estabilidade do nível de preços.

\section{3 Índice de Comunicação do Banco Central}

A mensuração da comunicação do banco central por meio de índices considera três importantes aspectos. O primeiro procura classificar todas as manifestações do banco central de acordo com o conteúdo e/ou sinalizações e, assim, usar uma escala numérica para codificar essas classificações. Estudos como os de Jansen e Haan (2005) e Ehrmann e Fratzscher (2007b), usam os códigos para indicar direção. Por outro lado, trabalhos como os de Rosa e Verga (2007) e Musard-Gies (2006) usam um código mais detalhado, por exemplo, variando numa escala de $-2 \mathrm{a}+2$.

O segundo aspecto importante procura analisar toda a forma de comunicação na mídia, feita pelo comitê ou seus membros, que seja importante para a política monetária (JANSEN; HAAN, 2005; EHRMANN; FRATZSCHER, 2007b). Nesse caso, são utilizadas agências de notícias especializadas, como a Reuters News, para extrair as declarações dos membros do comitê nos dias em que elas ocorrem. As extrações são feitas de forma mecânica usando um conjunto de palavras de busca que inclui o nome do membro do comitê de política monetária e os termos "taxa de juros", "política monetária" e "inflação", quando o objetivo é avaliar a inclinação da política monetária, e, mais ainda, "economia" e "perspectiva da economia", quando o objetivo é avaliar o ambiente econômico futuro.

O terceiro aspecto procura aproveitar algumas características institucionais de anúncio de política monetária para medir o impacto da comunicação. O trabalho de Brand, Buncic e Turunen (2006), por exemplo, separa os efeitos novidade e comunicação do ECB, porque, logo depois do encontro em que é decidida a taxa de juros, e durante o mesmo dia, o ECB anuncia e explica sua decisão em momentos diferentes. Às 13h45min publica a decisão de política monetária que consiste numa divulgação breve para a imprensa, em que fica conhecida a nova taxa de juros. Às 14h30min ocorre uma conferência para a imprensa na qual o presidente do ECB explica, com detalhes, os motivos da decisão, incluindo um resumo da situação econômica e monetária que respaldaram a decisão. Às 14h45min, a conferência para a imprensa é encerrada e são iniciados os questionamentos dos jornalistas. Dessa maneira, o intervalo de tempo permite separar a reação do mer- 
cado à divulgação da decisão (novidade) da reação do mercado à comunicação, usando-se dados intradiários da curva de rendimento.

O estudo de Rosa e Verga (2007) utiliza um índice discreto para analisar os comunicados do ECB. Com base na intensidade de risco para a estabilidade de preço, ou para o crescimento do produto, analisa a probabilidade de ação futura da política monetária, em outras palavras, mudanças na taxa básica de juros. $\mathrm{O}$ índice engloba cinco possibilidades: forte aumento, aumento, neutro, redução e forte redução da taxa de juros. A classificação é baseada em palavras-chave encontradas nos comunicados, com foco no conteúdo principal do comunicado. Após diagnosticar o teor do comunicado, são atribuídos os valores 2 (forte aumento), 1 (aumento), 0 (manutenção), -1 (redução) ou -2 (forte redução) para cada comunicado. Jansen e Haan (2005) utilizam uma metodologia semelhante para classificar os comunicados em relação à taxa de câmbio.

No trabalho de Heinemann e Ullrich (2007), foi apresentado o wording indicator (WI). Esse índice é baseado em palavras-código de acordo com o ciclo completo de alta e queda da taxa de juros do ECB. Os comunicados são analisados e é feita a seleção de palavras-código relacionadas com a frequência que em aparecem em cada etapa do ciclo, com o intuito de selecionar palavras-código com conteúdo informacional relevante. Após a seleção, as palavras-código são analisadas a partir do significant pair-wise tests, visando definir o sinal de cada palavra-código. Assim, sinais positivos são atribuídos àquelas palavras-código que possuem maior significância no período de alta, e valores negativos são atribuídos àquelas que possuem maior significância no período de queda. Em seguida, é aplicado um algoritmo ${ }^{7}$ para definir o valor do WI para cada comunicado.

Seguindo a mesma metodologia de Rosa e Verga (2007), os trabalhos de Costa Filho e Rocha (2009, 2010), Mendonça e Faria (2010) e Montes (2012) desenvolvem índices para classificar as atas do Copom e, assim, analisar a influência da comunicação sobre o comportamento das taxas de juros no Brasil.

O trabalho de Conrad e Lamla (2007) apresenta um indicador, baseado em uma codificação de cada declaração introdutória fornecida pelo instituto de pesquisa de mídia Mediatenor, encomendado pelo Konjunkturforschungsstelle (KOF). ${ }^{8}$ Esse indicador retira o conteúdo foward-looking dos discursos sobre risco para estabilidade de preços do presidente do ECB contendo informação sobre o pacote de política monetária futura. O índice varia de -1 a +1 , sendo que os maiores valores positivos (negativos) representam riscos para o aumento (queda) na estabilidade de preços.

7 Ver Heinemann e Ullrich (2007) para maiores informações sobre o algoritmo em questão.

8 O KOF é um instituto econômico na Suíça. KOF é um acrônimo para a palavra alemã Konjunkturforschungsstelle, que significa instituto de pesquisa em ciclo de negócios. 
As principais diferenças entre o indicador apresentado por Conrad e Lamla (2007) e o índice proposto neste trabalho estão relacionadas com o conteúdo contido no índice e a metodologia de construção (no presente trabalho é utilizada a teoria dos conjuntos fuzzy). Apesar de ser um índice contínuo, o indicador apresentado por Conrad e Lamla (2007) se limita a indicar sinais de política monetária futura, enquanto o índice proposto no presente trabalho fornece informações sobre a instabilidade geral do ambiente econômico em relação ao controle da inflação, sendo, assim, mais representativo para explicar a formação de expectativas para a inflação, uma vez que os agentes utilizam toda informação disponível para formar suas expectativas. Ademais, segundo Ullrich (2008), os agentes levam mais em consideração os riscos de inflação dos comunicados do que a intenção de política monetária para formar as expectativas de inflação.

\subsection{Metodologia da Formação do Índice de Comunicação}

O índice elaborado mensura, com base nas informações presentes nas atas do Copom, a percepção do Banco Central do Brasil em relação à estabilidade de preços. A metodologia utilizada para a construção do índice faz uso da teoria dos conjuntos fuzzy.

Ao se trabalhar com conceitos bem definidos, nos quais as regiões de pertinência dos elementos são definidas com alto grau de clareza, a teoria dos conjuntos convencional é uma aproximação satisfatória para a solução dos problemas propostos. Contudo, tratando-se de conceitos difusos, ou de difícil definição da região de pertinência, a teoria dos conjuntos fuzzy é um instrumental recomendado, uma vez que mitiga o risco de classificar o objeto no conjunto errado, pois este será pertinente em certo grau a um determinado conjunto. Como as atas do Copom possuem um conteúdo grande referente a diversos aspectos da economia, que se conectam em determinado grau, classificar essas atas em relação a uma única grandeza passa a ser uma tarefa que incorpora interpretação, com chances de uma classificação equivocada. Esse tipo de classificação equivocada é o que se pretende eliminar utilizando-se a teoria dos conjuntos fuzzy.

Um conjunto fuzzy é definido por um conjunto $X$ contendo elementos do tipo $X=\{x\}$, de forma que uma função $f(x)$ atribui valores do intervalo $[0,1]$ a cada elemento de $X$ de acordo com a pertinência ao conjunto. Para um elemento completamente pertinente, o valor atribuído é 1, e para um elemento completamente fora do conjunto, o valor atribuído é zero (ZADEH, 1965). Ademais, a teoria dos conjuntos fuzzy foi formalizada para criar uma teoria alternativa à teoria dos conjuntos convencionais, que utiliza a lógica binária para classificar a pertinência de um elemento a um conjunto. Na lógica fuzzy, existem graus de pertinência, de forma que um elemento não é classificado da forma pertence ou não pertence a 
um conjunto de forma exclusiva. Além de pertencer ou não, o elemento possui um grau de pertinência, de acordo com uma função numérica definida. Dessa forma, a teoria fuzzy dos conjuntos é útil para classificar conceitos difusos, que perdem informação se forem classificados de forma binária.

A metodologia aplicada para classificar as atas das reuniões do Copom parte de uma leitura minuciosa do conteúdo das atas. A leitura é realizada com o intuito de capturar o conteúdo sobre o controle da inflação contido em cada uma das atas. As atas são divididas em seções, e cada seção possui parágrafos numerados. Cada parágrafo tem seu conteúdo analisado como sendo otimista ou pessimista para o controle da inflação. No entanto, alguns parágrafos possuem conteúdo ambíguo, o que torna difícil a classificação do conteúdo. Por causa disso, esses parágrafos são descartados da análise, pois se entende que não pesam para um determinado lado em relação à percepção do banco central sobre o controle da inflação.

Após a análise de todo conteúdo da ata, é aplicada uma fórmula para mensurar o grau de perda de controle da inflação contida no ambiente econômico que foi comunicado pelo banco central. A fórmula consiste no número de parágrafos que teve o conteúdo considerado pessimista para o controle da inflação sobre o número total de parágrafos considerados. É importante destacar que a metodologia proposta não busca avaliar qual informação é mais relevante, dessa forma atribui o mesmo peso para todos os parágrafos. O índice tem valores entre 0 e 1 e é crescente na medida em que os riscos em relação ao controle da inflação aumentam, ou seja, quanto maior (menor) é o índice, significa que o banco central está mais pessimista (otimista) sobre o comportamento da inflação. Assim, o índice de comunicação do banco central (icbc) é:

$$
i c b c=\frac{\text { número de parágrafos pessimistas }}{\text { número total de parágrafos }}
$$

\section{Análise Empírica}

O período de análise compreende de maio de 2003 a fevereiro de 2012, com periodicidade mensal, totalizando 106 observações. A escolha do período está relacionada com a definição de um padrão para a publicação das atas, em termos de forma e periodicidade, as quais a partir de maio de 2003 passaram a ser publicadas sempre oito dias após o término da reunião. 


\subsection{Base de Dados}

As séries utilizadas são as seguintes:

a) desvio da expectativa de inflação em relação à meta $\left(E[\pi]-\pi^{*}\right)$ : série calculada a partir do desvio da expectativa de inflação em relação à meta de inflação para os próximos 12 meses. A série de expectativa de inflação é a expectativa média de inflação (do índice de preço ao consumidor ampliado - IPCA) acumulada para os próximos 12 meses, obtida no Banco Central do Brasil (BCB).

b) desvio da inflação em relação à meta $\left(\pi-\pi^{*}\right)$ : série calculada a partir do desvio da inflação (medida pelo IPCA) em relação à meta de inflação para os últimos 12 meses. A série para a inflação é a do IPCA em 12 meses série 13522 do $B C B$.

c) hiato do produto $\left(y-y^{*}\right)$ : com base na série do PIB acumulado nos últimos 12 meses a preços correntes em milhões de reais - série 4382 do $\mathrm{BCB}$ deflacionada pelo IPCA e dessazonalizada (Census X-12), foi aplicado o logaritmo natural na série e obtida sua tendência de longo prazo a partir do filtro Hodrick-Prescott. A seguir, foi calculado o desvio do produto em relação à sua tendência de longo prazo.

d) taxa Selic (ir): taxa Selic (taxa básica de juros) no mês acumulada em termos anuais - série 4189 do BCB. Representa o principal instrumento de política monetária.

e) taxa de câmbio real (€r): taxa de câmbio real efetiva indexada pelo IPCA com base em junho de $1994=101$ - série 11752 do BCB.

f) índice de reputação fiscal (irf): o irf é baseado no índice de reputação monetária apresentado por Mendonça e Souza (2009). O índice se baseia na concepção de que uma razão dívida/PIB acima de 60\%, de acordo com o Tratado de Maastricht, apresenta riscos para a sustentabilidade da dívida; por sua vez, uma razão abaixo de $40 \%$ seria sustentável, de acordo com o Fundo Monetário Internacional (FMI). ${ }^{9}$

9 De acordo com Chowdhury e Islam (2010, p. 1), "A debt-to-GDP ratio of 60 per cent has been proposed as a prudent limit for developed countries. It implies that crossing this limit will threaten fiscal sustainability. For developing and emerging economies, 40 per cent is the suggested debt-toGDP ratio. Based on these, an April 2010 report by the IMF's Fiscal Affairs Department offered illustrative 'fiscal adjustments' for economies to reach these suggested public debt-to-GDP ratios by 2030. Thus, there is a tendency to treat these debt-to-GDP ratios as 'optimal' in the specific sense that crossing these thresholds threatens debt sustainability. This is consistent with the IMF's global macroeconomic model which assigns a dual role to fiscal policy: (1) smoothening out business cycles in the short run; (2) meeting debt sustainability targets in the long run." 


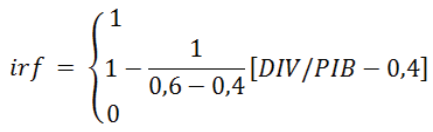$$
\left.\begin{array}{c}
\text { se } D I V / P I B=0,4 \\
\text { se } 0,4<D I V / P I B<0,6 \\
\text { se } D I V / P I B>0,6
\end{array}\right\}
$$

Para isso, foi utilizada a razão dívida/PIB (DIV/PIB), ou seja, a série da dívida líquida do setor público consolidado (\% PIB) - série 4513 do BCB.

g) desvio do câmbio nominal em relação ao seu valor natural ( $\epsilon \mathrm{n}$ - $\epsilon \mathrm{n}$ *): esta série foi obtida a partir da média do preço de compra do dólar americano - série 3695 do BCB - e do preço de venda do dólar americano - série 3696 do BCB. A série é calculada pelo desvio em relação ao seu valor natural, o qual foi obtido pelo filtro Hodrick-Prescott.

h) índice dos comunicados (icbc): utiliza-se o índice apresentado na seção anterior. A periodicidade das atas varia dentro do intervalo selecionado. Até o final de 2005, as atas eram publicadas mensalmente, após o início de 2006 as atas passaram a ser publicadas a cada 45 dias. De modo a ajustar a publicação das atas com a base de dados, a partir de 2006, para os meses nos quais não há publicação de ata, considera-se que os agentes utilizam a última informação disponível, ou seja, a ata do mês anterior. Dessa forma, o valor encontrado no índice é repetido para o mês que não há ata.

A Tabela 1 apresenta as estatísticas descritivas das séries utilizadas.

Tabela 1 - Estatísticas descritivas

\begin{tabular}{|c|c|c|c|c|c|}
\hline Series & Mean & Median & Maximum & Minimum & Std. Dev. \\
\hline$\left(\mathrm{E}[\Pi]-\Pi^{*}\right)$ & 0.31 & 0.31 & 1.80 & -1.10 & 0.70 \\
\hline$\left(\Pi-\Pi^{*}\right)$ & 1.12 & 0.97 & 11.24 & -1.99 & 2.23 \\
\hline$\left(\ln Y-\ln Y^{*}\right)$ & 0.00 & 0.00 & 0.02 & -0.03 & 0.01 \\
\hline IR & 13.93 & 12.70 & 26.31 & 8.65 & 4.00 \\
\hline $\mathbf{R e}$ & 97.38 & 95.08 & 144.29 & 69.30 & 21.51 \\
\hline IRF & 0.72 & 0.72 & 1.00 & 0.20 & 0.25 \\
\hline PD/GDP & 45.19 & 45.51 & 56.03 & 36.34 & 5.52 \\
\hline$\left(\epsilon-\epsilon^{*}\right)$ & 0.00 & $\begin{array}{c}- \\
0.01\end{array}$ & 0.50 & -0.33 & 0.16 \\
\hline ICBC & 0.50 & 0.50 & 0.69 & 0.24 & 0.10 \\
\hline
\end{tabular}

Fonte: Elaboração própria. 


\subsection{Metodologia de Análise}

De modo a evitar resultados espúrios e sem significado estatístico, a estacionariedade das séries foi testada. Foram realizados os testes Argumented Dickey-Fulley (ADF), Phillips-Perron (PP) e Kwiatkowski-Phillips-Schmidt-Shin (KPSS) (ver Tabela 8, no Apêndice A). A Tabela 2 apresenta um resumo dos resultados encontrados.

Tabela 2 - Tabela resumo para os testes de raiz unitária e estacionariedade

\begin{tabular}{|c|c|c|c|}
\hline Series & ADF & PP & KPSS \\
\hline$\left(E[\Pi]-\Pi^{*}\right)$ & $\mathrm{I}(0)$ & $\mathrm{I}(0)$ & $\mathrm{I}(0)$ \\
\hline$\left(\Pi-\Pi^{*}\right)$ & $\mathrm{I}(0)$ & $\mathrm{I}(0)$ & $\mathrm{I}(0)$ \\
\hline$\left(\ln Y-\ln Y^{*}\right)$ & $\mathrm{I}(0)$ & $\mathrm{I}(0)$ & $\mathrm{I}(0)$ \\
\hline IR & $\mathrm{I}(0)$ & $\mathrm{I}(0)$ & $\mathrm{I}(0)$ \\
\hline $\mathbf{R} \boldsymbol{\epsilon}$ & $\mathrm{I}(0)$ & $\mathrm{I}(0)$ & $\mathrm{I}(0)$ \\
\hline IRF & $\mathrm{I}(0)$ & $\mathrm{I}(0)$ & $\mathrm{I}(0)$ \\
\hline PD/GDP & $\mathrm{I}(1)$ & $\mathrm{I}(0)$ & $\mathrm{I}(0)$ \\
\hline$\left(\epsilon-\epsilon^{*}\right)$ & $\mathrm{I}(0)$ & $\mathrm{I}(0)$ & $\mathrm{I}(0)$ \\
\hline ICBC & $\mathrm{I}(1)$ & $\mathrm{I}(1)$ & $\mathrm{I}(1)$ \\
\hline
\end{tabular}

Fonte: Elaboração própria.

Para estimar as equações, foram utilizados os métodos $\mathrm{OLS}^{10}$ e GMM. Uma das razões para se utilizar o GMM é o fato de que esse método fornece estimadores consistentes para a regressão quando verificadas endogeneidades e não linearidade (HANSEN, 1982). Como apontado por Wooldridge (2001, p. 95), "[...] to obtain a more efficient estimator than two-stage least squares (or ordinary least squares), one must have overriding restrictions". A matriz de ponderação na equação foi escolhida para permitir que as estimativas por GMM sejam robustas, considerando a possível presença de heterocedasticidade e autocorrelação de forma desconhecida. ${ }^{11}$

10 As estatísticas $t$ reportadas na estimação por OLS são baseadas no estimador de Newey e West (1987), o qual é consistente na presença de heterocedasticidade e autocorrelação de forma desconhecida.

11 Ainda em relação à técnica empregada na estimação GMM, Cragg (1983) indica que a análise de sobreidentificação possui um importante papel na seleção das variáveis instrumentais para melhorar a eficiência dos estimadores. Sendo assim, o teste $J$ padrão foi realizado com o objetivo de testar essa propriedade para a validade das restrições de sobreidentificação (HANSEN, 1982). 


\subsection{Estimação da Formação de Expectativas de Inflação dos Agentes}

A equação estimada - equação 1 - para as expectativas de inflação tem como referência os trabalhos de Cerisola e Gelos (2005), Celasun, Gelos e Prati (2004a, 2004b) e Galí e Gertler (1999). No tocante às especificações, a escolha das defasagens foi determinada por meio da metodologia "geral para o específico", utilizando os critérios de informação tradicionalmente aplicados, além do princípio da parcimônia, e com base na teoria econômica. Ademais, foi considerado não somente a significância estatística dos parâmetros, mas também os testes de diagnósticos, com o intuito de assegurar que o modelo escolhido apresentasse poder explicativo (HENDRY, 2001). Pelo fato de o processo de formação de expectativas dos agentes ser condicionado pela informação disponível, então a informação contida nos comunicados do banco central deve ser incorporada na formação de expectativa dos agentes. $\mathrm{O}$ icbc utilizado para mensurar a informação contida nos comunicados possui valores entre 0 e 1 , sendo crescente em relação ao aumento dos riscos para o controle da inflação. Logo, espera-se que, quanto maior o valor do índice, maior o valor para a expectativa de inflação.

A equação estimada também leva em conta a influência da crise subprime desencadeada nos Estados Unidos. Para isso, é utilizada uma variável dummy (denominada subprime) que assume valor igual a 1, para o período de outubro de 2008 a agosto de 2009, e, zero, caso contrário. A escolha do período se deve à queda brusca nas expectativas, a qual pode ser explicada diretamente pela perda de dinamismo na economia por conta dos efeitos da crise. A equação a ser estimada é a seguinte:

$$
\begin{aligned}
& \left(\mathrm{E}[\pi]-\pi_{\mathrm{t}}^{*}\right)=\beta_{1}+\beta_{2}\left(\pi-\pi^{*}\right)_{\mathrm{t}-1}+\beta_{3} \mathrm{ir}_{\mathrm{t}-6}+\beta_{4}{\mathrm{DIV} / \mathrm{PIB}_{\mathrm{t}-3}}+\beta_{5}\left(\epsilon \mathrm{n}-\epsilon \mathrm{n}^{*}\right)_{\mathrm{t}-1}+\beta_{6}\left(\mathrm{y}-\mathrm{y}^{*}\right)_{\mathrm{t}-3}+\beta_{7} \\
& \mathrm{icbc}_{\mathrm{t}}+\beta_{8} \text { subprime }_{\mathrm{t}}+\varepsilon_{\mathrm{t}}
\end{aligned}
$$

em que $\varepsilon$ é o termo de erro aleatório e as derivadas parciais representam as relações esperadas:

$$
\begin{aligned}
& \frac{\partial\left(\mathrm{E}[\pi]-\pi^{*}\right)}{\partial\left(\pi-\pi^{*}\right)}>0 ; \frac{\partial\left(\mathrm{E}[\pi]-\pi^{*}\right)}{\partial i r}<0 ; \frac{\partial\left(\mathrm{E}[\pi]-\pi^{*}\right)}{\partial \mathrm{DIV} / \mathrm{PIB}}>0 ; \frac{\partial\left(\mathrm{E}[\pi]-\pi^{*}\right)}{\partial\left(\mathrm{en}-\mathrm{en}^{*}\right)}>0 ; \frac{\partial\left(\mathrm{E}[\pi]-\pi^{*}\right)}{\partial\left(\mathrm{y}-\mathrm{y}^{*}\right)}>0 ; \frac{\partial\left(\mathrm{E}[\pi]-\pi^{*}\right)}{\partial \mathrm{icbc}}> \\
& 0 \frac{\partial\left(\mathrm{E}[\pi]-\pi^{*}\right)}{\partial \text { subprime }}<0
\end{aligned}
$$

A Tabela 3 mostra os resultados das estimativas para a equação 1 . 
Tabela 3 - Estimativas OLS e GMM para a equação 1

\begin{tabular}{|c|c|c|}
\hline Variável & OLS & GMM \\
\hline \multirow{3}{*}{ CONSTANTE } & $* * *-2.400565$ & $* * *-2.17617$ \\
\hline & 0.786308 & 0.635933 \\
\hline & -3.052957 & -3.422011 \\
\hline \multirow{3}{*}{$\left(\Pi-\Pi^{*}\right)(-1)$} & $* * * 0.359376$ & $* * * 0.392829$ \\
\hline & 0.087231 & 0.067246 \\
\hline & 4.119818 & 5.841702 \\
\hline \multirow{3}{*}{$\operatorname{IR}(-6)$} & $* * *-0.104533$ & $* * *-0.099343$ \\
\hline & 0.022458 & 0.019692 \\
\hline & -4.654634 & -5.044758 \\
\hline \multirow{3}{*}{$\mathrm{PD} / \mathrm{GDP}(-3)$} & $* * * 0.074694$ & $* * * 0.06641$ \\
\hline & 0.021652 & 0.018564 \\
\hline & 3.449845 & 3.577384 \\
\hline \multirow{3}{*}{$\left(\epsilon-\epsilon^{*}\right)(-1)$} & $* * * 1.98865$ & $* * * 2.913418$ \\
\hline & 0.534984 & 0.372786 \\
\hline & 3.717214 & 7.815266 \\
\hline \multirow{3}{*}{$\left(\ln Y-\ln Y^{*}\right)(-3)$} & *13.74517 & $* * * 13.43375$ \\
\hline & 7.096976 & 4.815077 \\
\hline & 1.936764 & 2.789934 \\
\hline \multirow{3}{*}{ PIICBC } & $* * 1.238945$ & *1.447324 \\
\hline & 0.581031 & 0.78141 \\
\hline & 2.132323 & 1.852195 \\
\hline \multirow{3}{*}{ SUBPRIME } & $* * *-0.890571$ & $* * *-1.521707$ \\
\hline & 0.263009 & 0.323311 \\
\hline & -3.386081 & -4.706631 \\
\hline$R^{2}$ ajustado & 0.595714 & 0.58147 \\
\hline Teste F (p-valor) & 0 & \\
\hline Ramsey - RESET (1)(p-value) & 0.7907 & \\
\hline Jarque-Bera (p-value) & 0.1855 & \\
\hline ARCH (1)(p-value) & 0 & \\
\hline ARCH (2)(p-value) & 0 & \\
\hline ARCH (4)(p-value) & 0 & \\
\hline
\end{tabular}

continua... 
conclusão.

\begin{tabular}{l|rr}
\hline ARCH (8)(p-value) & 0 & \\
LM(1)(p-value) & 0 & \\
LM(2)(p-value) & 0 & 0.688523 \\
Prob(J-statistic) & & 27 \\
Rank & & \\
\hline
\end{tabular}

Fonte: Elaboração própria

Nota: Erro padrão entre parênteses e estatística t entre colchetes; Significância estatística:

$* * 0.01 ; * * 0.05 ; * 0.1$.

Em relação às estimativas por OLS, a estatística $F$ mostra que a equação estimada é significativa, e o resultado do teste Ramsey Reset indica que o modelo não apresenta problema de especificação. Em relação ao GMM, o resultado do teste $J$ indica que o modelo está corretamente especificado. ${ }^{12}$ A dummy (subprime) apresentou sinal esperado e significância estatística, o que justifica sua inclusão no modelo.

Quanto aos desvios da inflação passada em relação à meta de inflação, as evidências apontam uma relação direta e com significância estatística. Dessa forma, uma inflação maior no período passado eleva as expectativas de inflação no período atual. Esse resultado corrobora os achados apresentados por Cerisola e Gelos (2005). As estimativas para influência da taxa básica de juros - principal instrumento de política monetária para controle da inflação - sobre as expectativas de inflação apontam uma relação inversa (sinal negativo do coeficiente estimado) e com significância estatística. Portanto, a partir de um aumento (uma redução) na taxa básica de juros, é esperada uma redução (um aumento) das expectativas de inflação. O trabalho de Cerisola e Gelos (2005) também aponta para a existência dessa relação entre taxa de juros e expectativa de inflação.

Os resultados para a razão dívida/PIB apontam que o gerenciamento apropriado da política fiscal, no sentido de buscar a sustentabilidade da dívida pública, afeta as expectativas de inflação conforme o esperado. Em outras palavras, o gerenciamento da dívida voltado para sua sustentabilidade leva à redução das expectativas de inflação. Os coeficientes estimados apresentaram sinal positivo e significância estatística. Esses resultados indicam a importância da condução da política fiscal no regime de metas para inflação, pois o controle da dívida pública afeta as expectativas de inflação. Variáveis fiscais também foram testadas por Cerisola e Gelos (2005) e Celasun, Gelos e Prati (2004b), e os resultados confirmam seus achados.

12 Variáveis instrumentais utilizadas: $\left(\mathrm{E}[\pi]-\pi^{*}\right)_{-1},\left(\pi-\pi^{*}\right)_{-2},\left(\pi-\pi^{*}\right)_{-3},\left(\pi-\pi^{*}\right)_{-4},\left(\pi-\pi^{*}\right)_{-5},\left(\pi-\pi^{*}\right)_{-6}$

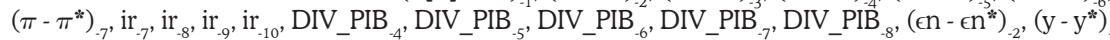
${ }_{4},\left(\mathrm{y}-\mathrm{y}^{*}\right)_{-5},\left(\mathrm{y}-\mathrm{y}^{*}\right)_{-6},\left(\mathrm{y}-\mathrm{y}^{*}\right)_{-7},\left(\mathrm{y}-\mathrm{y}^{*}\right)_{-8},\left(\bar{y}-\mathrm{y}^{*}\right)_{-9}, \mathrm{icbc}_{-1}, \mathrm{icbc}_{-2} \mathrm{e} \overline{\mathrm{icbc}}_{-3}$. 
As evidências encontradas para a influência dos desvios da taxa de câmbio sobre as expectativas de inflação apontam que se o câmbio se sobrevaloriza (subvaloriza), as expectativas para a inflação se reduzem (elevam). Os coeficientes estimados apresentaram sinal positivo e significância estatística. Resultado semelhante foi encontrado por Cerisola e Gelos (2005).

O hiato do produto é utilizado como medida para captar as pressões de demanda sobre a expectativa de inflação. Os resultados sugerem, com significância estatística, que, quando a economia se encontra aquecida (desaquecida), isto é, o produto está acima (abaixo) de sua tendência de longo prazo, serão formadas expectativas maiores (menores) para a inflação.

Em relação ao efeito da comunicação sobre as expectativas de inflação, os coeficientes estimados apresentaram sinal positivo e significância estatística. As evidências obtidas sugerem que, em períodos de instabilidade e de pressões inflacionárias, os comunicados, ao oferecer essas informações ao público, agem deteriorando as expectativas de inflação. Ou seja, ao comunicar que há dificuldades em relação ao controle da inflação, o banco central pode criar ainda maiores problemas para o controle da inflação, pois os comunicados agem elevando as expectativas de inflação, o que ressalta a importância do comprometimento que o banco central deve possuir em relação aos seus objetivos, de forma a manter as expectativas ancoradas. Portanto, as evidências apontam que a percepção do banco central acerca do comportamento da inflação afeta as expectativas de inflação formadas por experts do mercado financeiro.

\subsection{Paradoxo da Comunicação e Profecia Autorrealizável: Análise pela Curva de Phillips}

As evidências obtidas na seção anterior sugerem que a comunicação do banco central influencia as expectativas de inflação. Assim, com base nos resultados já encontrados, nesta seção e na seção seguinte é analisada a ideia de profecia autorrealizável e a situação paradoxal que envolve a comunicação. Ou seja, por meio do arcabouço teórico proposto pela curva de Phillips, o trabalho busca evidências acerca da influência da comunicação do banco central sobre a inflação por meio das expectativas de inflação e, portanto, acerca da ideia de que o conteúdo das informações comunicadas pelo banco central pode atuar desestabilizando as expectativas de inflação e enfraquecendo a âncora nominal, o que, em última instância, implicará efeitos sobre a inflação observada.

Quanto à ideia de profecia autorrealizável, trata-se de um prognóstico (ou um juízo antecipado) que, ao se tornar uma crença, provoca a sua própria concretização. Nesse sentido, quando o banco central espera (ou percebe) que algo acontecerá em relação à inflação (ou seja, apresenta uma percepção acerca do 
comportamento da inflação), os agentes econômicos agem como se a percepção (no caso, a "profecia") fosse algo tangível (provável de acontecer), e, assim, a percepção do banco central acaba por afetar as expectativas dos agentes e, por conseguinte, se realizar efetivamente. Portanto, o que o trabalho, por meio do indicador proposto, busca avaliar é o impacto da percepção do banco central quanto aos riscos de inflação (percepção extraída das informações presentes nas atas do Copom) sobre as expectativas de inflação formadas por experts do mercado e, por conseguinte, sobre a inflação. O esquema apresentado pela Figura 1 ilustra essa ideia.

Figura 1 - Percepção do banco central e profecia autorrealizável

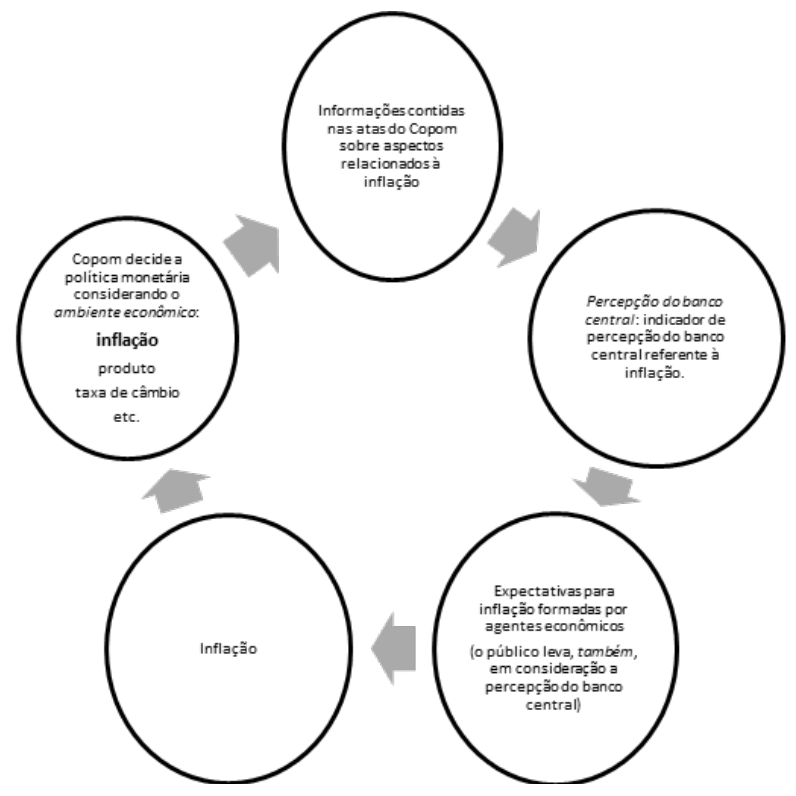

Fonte: Elaboração própria.

A equação 3 utilizada está baseada no trabalho de Mendonça e Valério (2010), o qual analisa uma curva de Phillips híbrida, ou seja, considera as expectativas de inflação (elemento forward-looking) e a inflação passada (elemento backward-looking). Entretanto, a equação utilizada no presente trabalho considera, como variável dependente, os desvios da inflação em relação à meta de inflação. Além disso, com base no trabalho de Bogdanski, Tombini e Werlang (2000), inclui, como variáveis de controle que influenciam a inflação, a taxa básica de juros (Selic) e a taxa de câmbio real, e, de forma inédita, propõe a utilização do índice de reputação fiscal como variável proxy representativa do lado fiscal. Ademais, foi incluída uma variável dummy que representa uma quebra estrutural advinda da 
consolidação da credibilidade do regime de metas para inflação no Brasil. A equação estimada é a seguinte:

$\left(\pi-\pi^{*}\right)_{\mathrm{t}}=\alpha_{1}+\alpha_{2}\left(\pi-\pi^{*}\right)_{\mathrm{t}-1}+\alpha_{3}\left(\mathrm{E}[\pi]-\pi^{*}\right)_{\mathrm{t}-1}+\alpha_{4}\left(\mathrm{y}-\mathrm{y}^{*}\right)_{\mathrm{t}-6}+\alpha_{5}$ ir $_{\mathrm{t}-9}+\alpha_{6} \in \mathrm{r}_{\mathrm{t}}+\alpha_{7} \mathrm{~d}_{-} \operatorname{irf}_{\mathrm{t}-6}+\alpha_{8} \mathrm{QUEBRA}_{\mathrm{t}}+\mu_{\mathrm{t}}$

em que $\mu$ é o termo de erro aleatório e as derivadas parciais representam as relações esperadas:

$$
\frac{\partial\left(\pi-\pi^{*}\right)}{\partial\left(\mathrm{E}[\pi]-\pi^{*}\right)}>0 ; \frac{\partial\left(\pi-\pi^{*}\right)}{\partial\left(\mathrm{y}-\mathrm{y}^{*}\right)}>0 ; \frac{\partial\left(\pi-\pi^{*}\right)}{\partial \mathrm{ir}}<0 ; \frac{\partial\left(\pi-\pi^{*}\right)}{\partial \epsilon \mathrm{r}}>0 ; \frac{\partial\left(\pi-\pi^{*}\right)}{\partial \mathrm{d}_{-} \text {irf }}<0 ; \frac{\partial\left(\pi-\pi^{*}\right)}{\partial \mathrm{QUEBRA}}>0
$$

A expectativa de inflação, a inflação passada e o hiato do produto correspondem à especificação da curva de Phillips híbrida convencional (MENDONÇA; VALÉRIO, 2010). A taxa de câmbio real possui influência contemporânea sobre a inflação, como ressalta Bogdanski, Tombini e Werlang (2000), de forma que uma valorização (desvalorização) cambial implica uma redução (aumento) da inflação, pois melhora (piora) os termos de troca, barateando (encarecendo) insumos e produtos importados.

Por sua vez, o índice de reputação fiscal mede o comprometimento do setor público com a saúde das finanças públicas. Dessa maneira, espera-se que um aumento no índice provoque uma redução na inflação e vice-versa.

Para identificar com maior acurácia o momento em que a consolidação da credibilidade do regime se reflete sobre o desvio da inflação em relação à meta, foi utilizado o teste de Chow para quebras estruturais - tal como feito por Montes e Bastos (2011), entretanto, estes analisaram o efeito sobre o spread da taxa de juros. Ou seja, o teste de Chow foi utilizado para identificar se houve quebra no comportamento da série relativa ao desvio da inflação em relação à meta. Nesse sentido, se analisa se houve uma mudança no intercepto da série. Para a realização do teste, seguiram-se os procedimentos de Montes e Bastos (2011). Assim, a série foi dividida em dois subperíodos (de maio de 2003 até novembro de 2006 e de dezembro de 2006 até fevereiro de 2012), de forma que, se for observada uma diferença significativa para as estimações relativas a cada subperíodo, há uma mudança estrutural na relação sob análise. O resultado obtido mostra que houve uma mudança estrutural, que indicou que o período correto para inserir a quebra é o mês de novembro de 2006 (ver Tabela 4). É importante notar (ver Tabela 5) que o teste foi feito também utilizando como data da quebra o período de dezembro de 2006, entretanto, a hipótese de não haver quebra para essa data não pode ser rejeitada a 1\%. Portanto, tal como feito por Montes e Bastos (2011) nessa mesma si- 
tuação, foi incluída uma dummy na regressão separando os dois períodos (de maio de 2003 até novembro de 2006 e de dezembro de 2006 até fevereiro de 2012) denominada dummy "quebra". A dummy assumiu valor igual a 1 a partir de maio de 2003 até novembro de 2006 e, 0, caso contrário. Assim, espera-se que a dummy de quebra apresente sinal positivo, pois representa o período inicial, o qual não havia consolidação da credibilidade do regime de metas e, portanto, expectativas de inflação e inflação mais elevadas.

Tabela 4 - Teste de quebra estrutural de Chow (novembro/2006)

\begin{tabular}{lllll}
\hline Variação nos regressores: & Todas as variáveis da equação & & \\
\hline Amostra & Maio/2003 - Fev/2012 & & \\
\hline F-Statistic & & 7.887 & Prob. & 0.0059 \\
\hline
\end{tabular}

Fonte: Elaboração própria.

Tabela 5 - Teste de quebra estrutural de Chow (dezembro/2006)

\begin{tabular}{|c|c|c|c|}
\hline Variação nos regressores: & Todas as variáveis da equação & & \\
\hline Amostra & Maio/2003 - Fev/2012 & & \\
\hline F-Statistic & 6.472 & $\begin{array}{r}\text { Prob. } \\
\mathrm{F}(1,104)\end{array}$ & 0.0124 \\
\hline
\end{tabular}

Fonte: Elaboração própria.

A Tabela 6 apresenta os resultados das estimativas para a equação 2. Quanto às estimativas por OLS, a estatística $F$ mostra que a equação estimada é significativa e o resultado do teste Ramsey Reset indica que o modelo não apresenta problema de especificação. Quanto ao GMM, o resultado do teste $J$ indica que o modelo está corretamente especificado. ${ }^{13}$ A dummy (QUEBRA) apresentou sinal esperado e significância estatística, o que justifica sua inclusão no modelo.

13 Variáveis instrumentais utilizadas: $\left(\pi-\pi^{*}\right)_{-2},\left(\mathrm{E}[\pi]-\pi^{*}\right)_{-2},\left(\mathrm{E}[\pi]-\pi^{*}\right)_{-3},\left(\mathrm{E}[\pi]-\pi^{*}\right)_{-4}, \mathrm{ir}_{-10}, \mathrm{ir}_{-11}, \mathrm{ir}_{-12}$, $\mathrm{ir}_{-13}, \mathrm{ir}_{-14}, \mathrm{ir}_{-15},\left(\mathrm{y}-\mathrm{y}^{*}\right)_{-7},\left(\mathrm{y}-\mathrm{y}^{*}\right)_{-8},\left(\mathrm{y}-\mathrm{y}^{*}\right)_{-9},\left(\mathrm{y}-\mathrm{y}^{*}\right)_{-10},\left(\mathrm{y}-\mathrm{y}^{*}\right)_{-11},\left(\mathrm{y}-\mathrm{y}^{*}\right)_{-12},\left(\mathrm{y}-\mathrm{y}^{*}\right)_{-13}, \mathrm{er}_{-1}, \mathrm{er}_{-2}, \mathrm{er}_{-3}, \mathrm{er}_{-4}$,

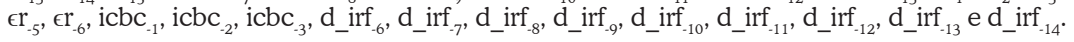


Tabela 6 - Estimativas OLS e GMM para equação (3)

\begin{tabular}{|c|c|c|}
\hline Variável & OLS & GMM \\
\hline \multirow[t]{3}{*}{ CONSTANTE } & $* * * 1.041065$ & $* * * 0.7874$ \\
\hline & 0.365097 & 0.245766 \\
\hline & 2.851478 & 3.203855 \\
\hline \multirow{3}{*}{$\left(\Pi-\Pi^{*}\right)(-1)$} & $* * * 0.751102$ & $* * * 0.779388$ \\
\hline & 0.052959 & 0.029561 \\
\hline & 14.18283 & 26.36584 \\
\hline \multirow{3}{*}{$\left(\mathrm{E}[\Pi]-\Pi^{*}\right)(-1)$} & *0.136167 & $* * 0.107348$ \\
\hline & 0.0767 & 0.053948 \\
\hline & 1.775325 & 1.989827 \\
\hline \multirow{3}{*}{$\left(\ln Y-\ln Y^{*}\right)(-6)$} & $* * * 12.34308$ & $* * * 9.658505$ \\
\hline & 3.884152 & 2.578356 \\
\hline & 3.177807 & 3.745994 \\
\hline \multirow[t]{3}{*}{$\operatorname{IR}(-9)$} & $* * *-0.108413$ & $* * *-0.094523$ \\
\hline & 0.023076 & 0.019872 \\
\hline & -4.698194 & -4.756591 \\
\hline \multirow[t]{3}{*}{$\mathrm{R} \epsilon$} & 0.004797 & $* * 0.00553$ \\
\hline & 0.003712 & 0.002206 \\
\hline & 1.292294 & 2.506695 \\
\hline \multirow[t]{3}{*}{$\mathrm{DIF}(\operatorname{IRF})(-6)$} & -2.008779 & $* *-1.668378$ \\
\hline & 1.242822 & 0.706262 \\
\hline & -1.616305 & -2.362263 \\
\hline \multirow[t]{3}{*}{ QUEBRA } & $* * * 0.534883$ & $* * * 0.42713$ \\
\hline & 0.190966 & 0.156484 \\
\hline & 2.800927 & 2.729556 \\
\hline$R^{2}$ ajustado & 0.95404 & 0.951275 \\
\hline Teste F (p-valor) & 0 & \\
\hline Ramsey - RESET (1)(p-value) & 0.9606 & \\
\hline Jarque-Bera (p-value) & 0.7444 & \\
\hline ARCH (1)(p-value) & 0.3518 & \\
\hline ARCH (2)(p-value) & 0.2496 & \\
\hline ARCH (4)(p-value) & 0.4753 & \\
\hline
\end{tabular}

continua... 
conclusão.

\begin{tabular}{|c|c|c|}
\hline ARCH (8)(p-value) & 0.2022 & \\
\hline LM(1)(p-value $)$ & 0 & \\
\hline $\operatorname{LM}(2)(p$-value $)$ & 0 & \\
\hline $\operatorname{Prob}(J$-statistic) & & 0.86338 \\
\hline Rank & & 33 \\
\hline
\end{tabular}

Fonte: Elaboração própria

Nota: Erro padrão entre parênteses e estatística t entre colchetes; Significância estatística: $* * * 0.01 ; * 0.05 ; * 0.1$.

As estimativas apresentam os sinais esperados, e só não há significância estatística para o câmbio real e o índice de reputação fiscal na estimação por OLS, entretanto, por GMM, os coeficientes passam a ser significativos. Em relação à reputação fiscal, por representar o comprometimento do governo com a sustentabilidade da dívida/PIB, uma redução nesse índice pode indicar que as finanças públicas estão entrando em trajetória insustentável, o que resultaria em pressões sobre a inflação e, portanto, em desvios da inflação em relação à meta de inflação.

As evidências apontam, com significância estatística, que os desvios da inflação passada em relação à meta de inflação e os desvios das expectativas de inflação em relação à meta de inflação possuem influência positiva sobre os desvios da inflação observada em relação à meta - esses resultados corroboram os achados de Celasun, Gelos e Prati (2004b). Sendo assim, é possível argumentar que os comunicados agem como profecias autorrealizáveis afetando diretamente as expectativas de inflação e indiretamente a inflação. Por sua vez, o "paradoxo da comunicação" se verifica, pois, ao comunicar, por exemplo, que existem pressões que dificultam o controle da inflação, o banco central fornece informações ao público que serão levadas em consideração no processo de formação de expectativas. Por conta dessas informações, há motivos para os agentes elevarem suas expectativas de inflação e repassarem para os preços na economia, gerando, com isso, inflação mais elevada. Ou seja, os comunicados do banco central que informam um contexto desfavorável em termos de inflação contaminam as expectativas de inflação, que, por sua vez, acabam afetando a inflação observada. A autoridade monetária não pode desconsiderar o fato de que as informações que revela são incorporadas nas expectativas do público e, portanto, devem agir de maneira comprometida com objetivos previamente estabelecidos. Nesse sentido, o banco central deve atuar comprometido com o objetivo de manter a inflação controlada, pois haverá um custo maior quando a inflação estiver acima da meta, uma vez que o banco central precisa prestar contas com a sociedade.

Em relação à influência da atividade econômica sobre os desvios da inflação em relação à meta, os coeficientes estimados para o hiato do produto apresenta- 
ram sinais positivos e significância estatística. Ou seja, um aumento no hiato do produto demonstra que a economia está aquecida e, portanto, gera pressões sobre a inflação.

Por sua vez, as estimativas para o efeito da política monetária sobre a inflação apresentaram os sinais esperados e significância estatística. Os resultados para a influência da política monetária corroboram os argumentos apresentados por Bogdanski, Tombini e Werlang (2000) acerca do tempo que leva para a política monetária afetar a inflação.

\subsection{Sistema de Equações}

Pelas estimações das equações individuais (equações 1 e 3, há evidências acerca da influência direta da comunicação do banco central sobre as expectativas de inflação e indireta sobre a taxa de inflação observada, por meio das expectativas de inflação. Ou seja, os resultados já obtidos sugerem as ideias de "paradoxo da comunicação" e profecia autorrealizável. Nesta seção, é estimado o mecanismo de transmissão de influência da comunicação do banco central sobre a inflação, por meio das expectativas de inflação, a partir de um sistema de equações, buscando, assim, conferir maior robustez aos resultados já encontrados. O sistema estimado é o seguinte:

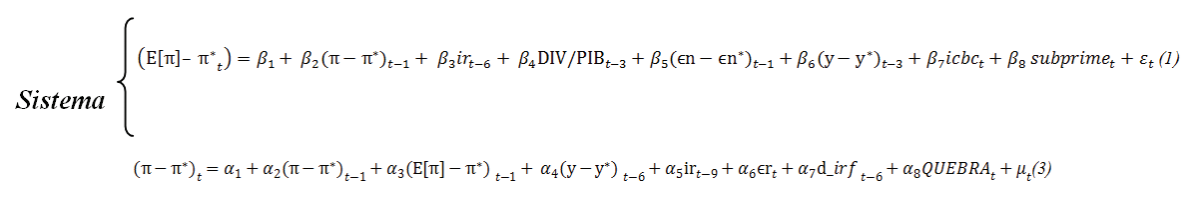

em que, $\vartheta$ e $\tau$ são os termos de erro aleatórios.

O sistema de equações é estimado por GMM de modo a corrigir os problemas de autocorrelação e endogeneidade, proporcionando, nesse sentido, coeficientes não viesados. ${ }^{14} \mathrm{~A}$ Tabela 7 apresenta os resultados.

14 O sistema estimado por GMM utiliza as mesmas variáveis instrumentais utilizadas nas estimações individuais. 
Tabela 7 - Estimação do sistema de equações por GMM

\begin{tabular}{|c|c|c|c|}
\hline \multicolumn{4}{|c|}{ GMM SYSTEM } \\
\hline Variável & $\mathbf{E}[\Pi]-\Pi^{*}$ & & $\left(\Pi-\Pi^{*}\right)$ \\
\hline \multirow{3}{*}{ CONSTANTE } & $* * *-2.309293$ & & $* * * 0.736648$ \\
\hline & 0.397055 & CONSTANTE & 0.180007 \\
\hline & -5.816051 & & 4.092332 \\
\hline \multirow{3}{*}{$\left(\Pi-\Pi^{*}\right)(-1)$} & $* * * 0.439295$ & & $* * * 0.787898$ \\
\hline & 0.038819 & $\left(\Pi-\Pi^{*}\right)(-1)$ & 0.026794 \\
\hline & 11.31656 & & 29.40603 \\
\hline \multirow{3}{*}{$\operatorname{IR}(-6)$} & $* * *-0.09418$ & & $* * * 0.118157$ \\
\hline & 0.010614 & $\left(E[\Pi]-\Pi^{*}\right)(-1)$ & 0.040646 \\
\hline & -8.873199 & & 2.906981 \\
\hline \multirow{3}{*}{ PD/GDP (-3) } & $* * * 0.063586$ & & $* * * 9.966319$ \\
\hline & 0.010626 & $\left(\ln Y-\ln Y^{*}\right)(-6)$ & 1.936563 \\
\hline & 5.984096 & & 5.146396 \\
\hline \multirow{3}{*}{$\left(\epsilon-\epsilon^{*}\right)(-1)$} & $* * * 3.09411$ & & $* * *-0.082748$ \\
\hline & 0.214954 & $\operatorname{IR}(-9)$ & 0.01418 \\
\hline & 14.39426 & & -5.835707 \\
\hline \multirow{3}{*}{$\left(\ln Y-\ln Y^{*}\right)(-3)$} & $* * * 10.67632$ & & $* * * 0.004611$ \\
\hline & 3.114922 & $\mathrm{R} \epsilon$ & 0.001509 \\
\hline & 3.427478 & & 3.056063 \\
\hline \multirow{3}{*}{ PIICBC } & $* * * 1.758798$ & & $* * *-1.795801$ \\
\hline & 0.452886 & $\operatorname{DIF}(\operatorname{IRF})(-6)$ & 0.530686 \\
\hline & 3.88353 & & -3.383924 \\
\hline \multirow{3}{*}{ SUBPRIME } & $* * *-1.458904$ & & $* * * 0.349878$ \\
\hline & 0.179755 & QUEBRA & 0.111398 \\
\hline & -8.116067 & & 3.140786 \\
\hline$R^{2}$ ajustado & 0.606542 & & 0.955587 \\
\hline $\operatorname{Prob}(J$-statistic) & & 0.995903183 & \\
\hline
\end{tabular}

Fonte: Elaboração própria.

Nota: Erro padrão entre parênteses e estatística $t$ entre colchetes; Significância estatística: $* * 0.01 ; * 0.05 ; * 0.1$. 
Os sinais dos coeficientes estimados corroboram aqueles encontrados nas estimações individuais. Ademais, é observado que os erros padrão foram reduzidos e as estimações foram obtidas com maior acurácia por meio do sistema.

As evidências apontam que a comunicação do banco central afeta as expectativas de inflação, as quais afetam a inflação observada. Desse modo, a ideia de profecia autorrealizável é também observada por meio dos resultados do sistema, assim como o paradoxo da comunicação. Se, por um lado, o banco central comunica que a inflação está controlada, então essa comunicação é importante para guiar as expectativas dos agentes em direção à meta de inflação e, assim, fortalecer a âncora nominal, proporcionando credibilidade ao regime e ao banco central. Por outro lado, caso o banco central comunique que a inflação está fugindo ao controle, então esse conteúdo informado pode atuar desestabilizando as expectativas e enfraquecendo a âncora nominal.

\section{Considerações Finais}

Após analisar a literatura sobre comunicação do banco central, é possível observar uma lacuna no tocante aos estudos empíricos referentes à influência dos comunicados do banco central sobre as expectativas de inflação, sobretudo para países emergentes. O presente trabalho buscou suprir essa lacuna, analisando os efeitos do conteúdo das atas do Copom sobre as expectativas de inflação e, por conseguinte, sobre a própria inflação.

Os resultados sugerem o paradoxo da comunicação e indicam que os comunicados do banco central possuem um caráter de profecia autorrealizável. Além de obter significância estatística em todos os modelos e métodos estimados, o sinal positivo apresentado pelo índice de comunicação mostra que as expectativas de inflação seguem as informações contidas nos comunicados em relação ao ambiente econômico. Ou seja, o que é relatado pelo banco central - seja sobre a situação da inflação, do produto e de outras variáveis - é incorporado às expectativas do público.

Além de inserir um novo método de mensurar o conteúdo das atas do Copom, este trabalho indica resultados com implicações importantes para a estratégia de comunicação do banco central. As expectativas dos agentes reagem no sentido indicado pelo comunicado, de forma que os comunicados provocam deterioração das expectativas em momentos de instabilidade, assim como provocam ancoragem das expectativas quando a inflação está controlada. O presente estudo não é a favor da opacidade; pelo contrário, a transparência é fundamental para o fortalecimento da democracia e para a confiança do público em relação ao Estado. Entretanto, as autoridades devem estar cientes que aquilo que revelam é incorporado às expectativas do público e, portanto, devem agir de maneira com- 
prometida com objetivos críveis previamente estabelecidos. Nesse sentido, o banco central deve aumentar seus incentivos para manter a inflação controlada, pois há um custo maior quando a inflação está acima da meta, uma vez que o banco central precisa prestar contas para o público.

\section{Referências}

BERGER, H.; EHRMANN, M.; FRATZSCHER, M. Monetary Policy in the Media. Journal of Money, Credit and Banking, v. 43, n. 4, p. 689-709, 2011.

BERGER, H.; HAAN, J.; STURM, J. E. Does money matter in the ECB strategy? New evidence based on ECB communication. International Journal of Finance and Economics, v. 16, n.1p. 16-31, 2011.

BLINDER, A. et al. Central bank communication and monetary policy: a survey of theory and evidence. Journal of Economic Literature, American Economic Association, vol. 46(4), pages 910-45, December 2008.

BLINDER, A. S. Monetary policy by Committee: why and how? European Journal of Political Economy, v. 23, n. 1, p. 106-23, 2007.

BOGDANSKI, J.; TOMBINI, A.; WERLANG, S. R. Implementing inflation targeting in Brazil. Brasilia, DF: Banco Central do Brasil, 2000. (Working Paper,n. 1).

BRAND, C.; BUNCIC, D.; TURUNEN, J. The impact of ECB monetary policy decisions and communication on the Yield Curve. Journal of the European Economic Association, v. 8, n. 6, p. 1266-1298, 2010.

CELASUN, O. R.; GELOS, G.; PRATI, A. Obstacles to disinflation: what is the role of fiscal expectations? Economic Policy, v. 19, p. 441-81, 2004a.

CELASUN, O. R.; GELOS, G.; PRATI, A. Would 'Cold Turkey’ work in Turkey? IMF Staff Papers, v. 51, n. 3, p. 493-509, 2004b.

CERISOLA, M.; GELOS, R. G. What drives inflation expectation in Brazil? An empircal analisys. Washington, DC: IMF, 2005. (IMF Working Paper, n. 05/109).

CHOWDHURY, A.; ISLAM, I. An optimal debt-to-GDP ratio? G-24 Policy Brief, n. 66, p.1 -4, 2010.

CONNOLLY, E.; KOHLER, M. News and interest rate expectations: a study of six Central Banks. In: KENT, C.; SIMON, G. (Ed.). The future of inflation targeting. Sydney: Reserve Bank of Australia, 2004. (RBA, Annual Conference Volume).

CONRAD, C.; LAMLA, M. J. The high-frequency response of the EUR-US Dollar exchange rate to ECB monetary policy announcements. Zurich: KOF Swiss Economic Institute; ETH Zurich, 2007. (Working Paper, 07-174).

COSTA FILHO, A. E.; ROCHA, F. F. Como o mercado de juros reage à comunicação do Banco Central? Economia Aplicada, v. 14, n. 3, p. 265-292, 2010. 
. Comunicação e política monetária no Brasil. Revista Brasileira de Economia, v. 63, n. 4, p. 405-4022, 2009.

CRAGG, J. G. More efficient estimation in the presence of heteroscedasticity of unknown form. Econometrica, v. 51, n. 3, p. 751-763, 1983.

EHRMANN, M.; FRATZSCHER, M. Communication by central bank committee members: different strategies, same effectiveness. Journal of Money, Credit and Banking, v. 39, n. 2-3, p. 509-541, 2007b.

. Purdah: on the rationale for Central Bank silence around policy meetings. Journal of $\overline{\text { Money, }}$ Credit and Banking, v. 41, n. 2-3, p. 517-528, 2009.

. The timing of Central Bank communication. European Journal of Political Economy, v. 23, n. 1, p. 124-45, 2007a.

FRATZSCHER, M. Oral interventions versus actual interventions in FX Markets: an eventstudy approach. The Economic Journal, v. 188, n. 530, p. 1079-1106, 2008.

FUJIWARA, I. Is the Central Bank's publication of economic forecasts influential? Economics Letters, v. 89, n. 3, p. 255-261, 2005.

GALÍ, J.; GERTLER, M. Inflation dynamics: a structural econometric analysis. Journal of Monetary Economics, v. 44, n. 2, p. 195-222, Oct. 1999.

GERAATS, P. Central Bank transparency. Economic Journal, v. 112, n. 483, p. 532-565, 2002.

GÜRKAYNAK, R. S.; SACK, B.; SWANSON, E. T. Do actions speak louder than words? The response of asset prices to monetary policy actions and statements. International Journal of Central Banking, v.1, n. 1, p. 55-93, May 2005.

GUTHRIE, G.; WRIGHT, J. Open mouth operations. Journal of Monetary Economics, v. 46, n. 2, p. 489-516, 2000.

HANSEN, L. P. Large sample properties of generalized method of moments estimators. Econometrica, v. 50, n. 4, p. 1029-1054, 1982.

HAYO, B.; KUTAN, A. M.; NEUENKIRCH, M. The impact of U.S. Central Bank communication on European and pacific equity markets. Economics Letters, v. 108, n. 2, p. 172-174, 2010.

HAYO, B.; NEUENKIRCH, M. Bank of Canada communication, media coverage, and financial market reactions. Economic Letters, v. 115, n. 3, p. 369-372, 2010.

HEINEMANN, F.; ULLRICH, K. Does it pay to watch Central Bankers lips? The information content of ECB wording. Swiss Journal of Economics, v. 143, n. 2, p. 155-185, 2007.

JANOT, M.; MOTA, D. S. O impacto da comunicação do Banco Central do Brasil sobre o mercado financeiro. Brasília, DF: Bacen, 2012. (Trabalhos para Discussão do Banco Central do Brasil, n. 265). 
JANSEN, D. Does the clarity of Central Bank communication affect volatility in financial markets? Evidence from Humphrey-Hawkins Testimonies. Contemporary Economic Policy, v. 29, n. 4, p. 494-509, 2011.

JANSEN, D.; HAAN, J. Talking heads: the effects of ECB statements on the Euro-Dollar exchange rate. Journal of International Money and Finance, v. 24, n. 2, p. 343-361, 2005.

. The importance of being vigilant: Has ECB communication influenced euro area inflation expectations? Munich: CESifo, 2007b. (Technical Report).

. Were verbal efforts to support the Euro effective? A high-frequency analysis of ECB statements. European Journal of Political Economy, v. 23, n. 1, p. 245-259, 2007 a.

KOHN, D. L.; SACK, B. Central Bank talk: does it matter and why? In: BANK OF CANADA. Macroeconomics, monetary policy, and financial stability. Ottawa: Bank of Canada, 2004. p. 175-206.

MENDONÇA, H. F.; FARIA, I. Effects of the Brazilian Central Bank communication on financial markets expectations. In: ENCONTRO BRASILEIRO DE ECONOMETRIA, 32., 2010, Salvador. Anais... Salvador: SBE, 2010.

. Transparência, comunicação e formação de expectativas: consequências para a política monetária. Ensaios FEE, v. 32, n. 2, p. 553-574, 2011.

MENDONÇA, H. F.; SIMÃO FILHO, J. Economic transparency and effectiveness of monetary policy. Journal of Economic Studies, v. 34, n. 6, p. 497-514. 2007.

MENDONÇA, H. F.; SOUZA, G. J. G. Inflation targeting credibility and reputation: the consequences for the interest rate. Economic Modelling, v. 26, p. 1228-1238, 2009.

MENDONÇA, H. F.; VALERIO, D. What kind of Phillips curve works in the Brazilian inflation targeting? The Empirical Economics Letters, n. 9, p. 803-809, 2010.

MISHKIN, F. S.; SAVASTANO, M. A. Monetary policy strategies for Latin America. Journal of Development Economics, v. 66, n. 2, p. 415-444, 2001.

MONTES, G. C. Financial market reaction to central bank communication and monetary policy: evidence for an inflation targeting emerging economy. CEPAL Review, n. 107, p. 165181, Aug. 2012.

MONTES, G. C.; BASTOS, J. C. A. Metas de inflação e estrutura a termo das taxas de juros no Brasil. Economia Aplicada, v. 15, n. 3, p. 391-415, 2011.

MUSARD-GIES, M. Do European Central Bank's Statements Steer Interest Rates In The Euro Zone? Manchester School, v. 74, n. 1, p. 116-139, 2006.

RANALDO, A.; ROSSI, E. The reaction of asset markets to Swiss National Bank communication. Journal of International Money and Finance, v. 29, n. 3, p. 486-503, 2010.

REEVES, R.; SAWICKI, M. Do financial markets react to Bank of England Communication? European Journal of Political Economy, v. 23, n. 1, p. 207-27, 2007. 
ROSA, C. Words that shake traders. Journal of Empiric Finance, v. 18, n. 5, p. 915-934, 2011.

ROSA, C.; VERGA, G. On the consistency and effectiveness of Central Bank communication: evidence from the ECB. European Journal of Political Economy, v. 23, n. 1, 146-75, p. 2007.

ROZKRUT, M. et al. Quest for central bank communication: does it pay to be "talkative"? European Journal of Political Economy, v. 23, n. 1, p. 176-206, 2007.

STURM, J.; HAAN, J. Does Central Bank communication really lead to better forecasts of policy decisions? New evidence based on a Taylor rule model for the ECB. Review of World Economics (Weltwirtschaftliches Archiv), v. 147, n. 1, p. 41-58, 2011.

ULLRICH, K. Inflation expectations of experts and ECB communication. North American Journal of Economics and Finance, v. 19, n. 1, p. 93-108, 2008.

WOODFORD, M. Interest and prices: foundations of a theory of monetary policy. Princeton: Princeton University Press, 2003.

ZADEH, L. A. Fuzzy sets. Information and Control, n. 8, p. 338-353, 1965.

\section{Apêndice A}

Tabela 8 - Testes de raiz unitária e estacionariedade

\begin{tabular}{|c|c|c|c|c|c|c|c|c|c|c|c|c|c|c|}
\hline & \multicolumn{4}{|c|}{ ADF } & \multicolumn{4}{|c|}{ PP } & \multicolumn{6}{|c|}{ KPSS } \\
\hline & Lag & Forma & Teste & Prob & Forma & Bandwidth & Teste & Prob & Forma & Bandwidth & Teste & $1 \%$ & $5 \%$ & $10 \%$ \\
\hline$\left(E[\pi]-\pi^{*}\right)$ & 1 & $N$ & $-1,958$ & 0,049 & $N$ & 3 & $-2,159$ & 0,030 & $\mathrm{C}$ & 8 & 0,191 & 0,739 & 0,463 & 0,347 \\
\hline ir & 2 & $C T$ & $-4,384$ & 0,004 & C & 7 & $-3,076$ & 0,032 & CT & 8 & 0,140 & 0,216 & 0,146 & 0,119 \\
\hline$\left(\boldsymbol{\epsilon} \mathbf{n}-\boldsymbol{\epsilon}^{*}\right)$ & 0 & $N$ & $-2,913$ & 0,004 & $N$ & 4 & $-3,317$ & 0,001 & $\mathrm{C}$ & 7 & 0,044 & 0,739 & 0,463 & 0,347 \\
\hline DIV/PIB & 0 & $N$ & $-3,282$ & 0,001 & $N$ & 1 & $-3,109$ & 0,002 & CT & 8 & 0,130 & 0,216 & 0,146 & 0,119 \\
\hline$i c b c$ & 0 & $\mathrm{C}$ & $-5,559$ & 0,000 & $\mathrm{C}$ & 4 & $-5,513$ & 0,000 & $\mathrm{C}$ & 4 & 0,072 & 0,739 & 0,463 & 0,347 \\
\hline$\left(y-y^{*}\right)$ & 3 & $N$ & $-3,778$ & 0,000 & $N$ & 7 & $-2,589$ & 0,010 & $\mathrm{C}$ & 8 & 0,042 & 0,739 & 0,463 & 0,347 \\
\hline$\left(\pi-\pi^{*}\right)$ & 12 & $\mathrm{~N}$ & $-1,561$ & 0,111 & $\mathrm{~N}$ & 7 & $-4,789$ & 0,000 & $\mathrm{C}$ & 8 & 0,225 & 0,739 & 0,463 & 0,347 \\
\hline er & 0 & $\mathrm{~N}$ & $-2,227$ & 0,026 & $\mathrm{~N}$ & 2 & $-2,029$ & 0,041 & CT & 8 & 0,173 & 0,216 & 0,146 & 0,119 \\
\hline irf & 0 & $\mathrm{C}$ & $-1,960$ & 0,304 & $\mathrm{C}$ & 0 & $-1,960$ & 0,304 & CT & 8 & 0,212 & 0,216 & 0,146 & 0,119 \\
\hline d_irf & 0 & $\mathrm{C}$ & $-8,885$ & 0,000 & $\mathrm{C}$ & 1 & $-8,893$ & 0,000 & $\mathrm{C}$ & 3 & 0,261 & 0,739 & 0,463 & 0,347 \\
\hline
\end{tabular}

Fonte: Elaboração própria.

Nota: $C$ denota constante; $C T$ denota constante e tendência; e $N$ denota nenhum; ADF: a escolha final de defasagem foi feita baseada no critério de Schwarz; PP e KPSS: a escolha final foi feita baseada no critério de Schwarz; a defasagem é o lag truncation escolhido para o Bartlett kernel. 
Quadro 1 - Quadro síntese de referências da literatura

\begin{tabular}{|c|c|c|c|c|}
\hline Referência & Objetivo & Metodologia & $\begin{array}{c}\text { Índice de } \\
\text { comunica- } \\
\text { ção }\end{array}$ & Resultado \\
\hline \multicolumn{5}{|c|}{ Estudos sobre taxas de juros } \\
\hline $\begin{array}{l}\text { Guthrie } \\
\text { e Wright } \\
\text { (2000) }\end{array}$ & $\begin{array}{l}\text { Analisar a in- } \\
\text { fluência dos } \\
\text { comunicados } \\
\text { sobre as taxas } \\
\text { de juros. }\end{array}$ & $\begin{array}{l}\text { Estudo de } \\
\text { evento em } \\
\text { dados de alta } \\
\text { frequência. }\end{array}$ & $\begin{array}{l}\text { Índice para } \\
\text { política } \\
\text { monetária } \\
\text { futura com } \\
\text { valores }-1,0 \\
\text { e } 1 .\end{array}$ & $\begin{array}{l}\text { Comunica- } \\
\text { ção do ban- } \\
\text { co central é } \\
\text { capaz de afe- } \\
\text { tar as taxas } \\
\text { de juros. }\end{array}$ \\
\hline $\begin{array}{l}\text { Kohn e Sack } \\
\quad(2004)\end{array}$ & $\begin{array}{c}\text { Analisar a in- } \\
\text { fluência dos } \\
\text { comunicados } \\
\text { sobre as variá- } \\
\text { veis financeiras } \\
\text { (taxas de juros, } \\
\text { câmbio e mer- } \\
\text { cado de ações). }\end{array}$ & $\begin{array}{l}\text { Estudo de } \\
\text { evento em } \\
\text { dados de alta } \\
\text { frequência. }\end{array}$ & $\begin{array}{l}\text { Dummy para } \\
\text { o dia que } \\
\text { possui comu- } \\
\text { nicados. }\end{array}$ & $\begin{array}{c}\text { Comuni- } \\
\text { cação do } \\
\text { banco cen- } \\
\text { tral é capaz } \\
\text { de afetar a } \\
\text { volatilidade } \\
\text { das taxas de } \\
\text { juros de cur- } \\
\text { to e médio } \\
\text { prazo. }\end{array}$ \\
\hline $\begin{array}{l}\text { Andersson, } \\
\text { Dillén e } \\
\text { Sellin (2006) }\end{array}$ & $\begin{array}{l}\text { Analisar a in- } \\
\text { fluência dos } \\
\text { comunicados } \\
\text { sobre a estrutu- } \\
\text { ra a termo da } \\
\text { taxa de juros. }\end{array}$ & $\begin{array}{l}\text { Estimação por } \\
\text { OLS com da- } \\
\text { dos semanais. }\end{array}$ & $\begin{array}{c}\text { Índice } \\
\text { construído } \\
\text { para analisar } \\
\text { a surpresa } \\
\text { da política } \\
\text { monetária. }\end{array}$ & $\begin{array}{c}\text { Comunica- } \\
\text { ção do ban- } \\
\text { co central é } \\
\text { mais eficaz } \\
\text { afetando as } \\
\text { taxas de ju- } \\
\text { ros de termo } \\
\text { longo. }\end{array}$ \\
\hline $\begin{array}{l}\text { Musard-Gies } \\
\quad(2006)\end{array}$ & $\begin{array}{l}\text { Analisar o efeito } \\
\text { dos comuni- } \\
\text { cados do ECB } \\
\text { sobre as taxas } \\
\text { de juros de } \\
\text { mercado. }\end{array}$ & $\begin{array}{c}\text { Estudo de } \\
\text { evento em } \\
\text { dados de alta } \\
\text { frequência e } \\
\text { estimações } \\
\text { não-paramé- } \\
\text { tricas. }\end{array}$ & $\begin{array}{l}\text { Índice para } \\
\text { política } \\
\text { monetária } \\
\text { futura com } \\
\text { valores }-1,0 \\
\text { e } 1 .\end{array}$ & $\begin{array}{l}\text { Os mercados } \\
\text { respondem } \\
\text { na direção } \\
\text { indicada nos } \\
\text { comunica- } \\
\text { dos, prin- } \\
\text { cipalmente } \\
\text { quando há } \\
\text { variação } \\
\text { entre uma } \\
\text { reunião e } \\
\text { outra. }\end{array}$ \\
\hline
\end{tabular}


continuação...

\begin{tabular}{|c|c|c|c|c|}
\hline $\begin{array}{l}\text { Ehrmann e } \\
\text { Fratzscher } \\
(2007 a)\end{array}$ & $\begin{array}{l}\text { Verificar sobre } \\
\text { quais circuns- } \\
\text { tâncias a co- } \\
\text { municação do } \\
\text { banco central } \\
\text { é capaz de } \\
\text { influenciar os } \\
\text { mercados finan- } \\
\text { ceiros. }\end{array}$ & $\begin{array}{c}\text { Estimação por } \\
\text { E-GARCH com } \\
\text { dados de alta } \\
\text { frequência. }\end{array}$ & $\begin{array}{c}\text { Índice para } \\
\text { política } \\
\text { monetária } \\
\text { futura e } \\
\text { pressão } \\
\text { inflacionária } \\
\text { com valores } \\
\text {-1, } 0 \text { e } 1 .\end{array}$ & $\begin{array}{l}\text { Comuni- } \\
\text { cados que } \\
\text { antecedem } \\
\text { decisões so- } \\
\text { bre a política } \\
\text { monetária } \\
\text { possuem } \\
\text { efeito maior } \\
\text { sobre os } \\
\text { mercados. }\end{array}$ \\
\hline $\begin{array}{l}\text { Ehrmann e } \\
\text { Fratszcher } \\
\text { (2007b) }\end{array}$ & $\begin{array}{l}\text { Avaliar a eficá- } \\
\text { cia da comu- } \\
\text { nicação por } \\
\text { diferentes estra- } \\
\text { tégias. }\end{array}$ & $\begin{array}{l}\text { Estimação por } \\
\text { E-GARCH com } \\
\text { dados de alta } \\
\text { frequência. }\end{array}$ & $\begin{array}{c}\text { Índice para } \\
\text { política } \\
\text { monetária } \\
\text { futura e } \\
\text { pressão } \\
\text { inflacionária } \\
\text { com valores } \\
\text {-1, o e } 1 .\end{array}$ & $\begin{array}{l}\text { Os diferentes } \\
\text { tipos de es- } \\
\text { tratégia, co- } \\
\text { municação } \\
\text { colegiada ou } \\
\text { individual, } \\
\text { não afetam } \\
\text { seu efeito } \\
\text { sobre o mer- } \\
\text { cado. }\end{array}$ \\
\hline $\begin{array}{l}\text { Rosa e Ver- } \\
\text { ga (2007) }\end{array}$ & $\begin{array}{c}\text { Analisar o } \\
\text { impacto do } \\
\text { conteúdo dos } \\
\text { comunicados } \\
\text { sobre o merca- } \\
\text { do financeiro. }\end{array}$ & $\begin{array}{l}\text { Estimações por } \\
\text { OLS e dados } \\
\text { com alta fre- } \\
\text { quência. }\end{array}$ & $\begin{array}{c}\text { Índice para } \\
\text { a política } \\
\text { monetária } \\
\text { futura } \\
\text { baseado em } \\
\text { informações } \\
\text { de um } \\
\text { glossários, } \\
\text { recebendo os } \\
\text { valores -2, -1, } \\
0,1 \text { e } 2 \text {. }\end{array}$ & $\begin{array}{l}\text { A informa- } \\
\text { ção dos co- } \\
\text { municados } \\
\text { do ECB é } \\
\text { relevante } \\
\text { e capaz de } \\
\text { mover os } \\
\text { mercados. }\end{array}$ \\
\hline
\end{tabular}

continua.. 


\begin{tabular}{|c|c|c|c|c|}
\hline $\begin{array}{l}\text { Heinemann } \\
\text { e Ullrich } \\
(2007)\end{array}$ & $\begin{array}{l}\text { Avaliar o efeito } \\
\text { da comunica- } \\
\text { ção dentro de } \\
\text { uma regra de } \\
\text { reação da polí- } \\
\text { tica monetária. }\end{array}$ & $\begin{array}{l}\text { Dados mensais } \\
\text { estimados por } \\
\text { Probit. }\end{array}$ & $\begin{array}{l}\text { Wording indi- } \\
\text { cator: índice } \\
\text { baseado na } \\
\text { contagem } \\
\text { de palavras } \\
\text { que reflete a } \\
\text { inclinação da } \\
\text { política mo- } \\
\text { netária. }\end{array}$ & $\begin{array}{c}\text { Regra de } \\
\text { Taylor não } \\
\text { é capaz de } \\
\text { explicar } \\
\text { sozinha a } \\
\text { decisão so- } \\
\text { bre a política } \\
\text { monetária } \\
\text { e o wording } \\
\text { indicator } \\
\text { possui rele- } \\
\text { vância nessa } \\
\text { análise. }\end{array}$ \\
\hline $\begin{array}{c}\text { Sturm e } \\
\text { Haan (2011) }\end{array}$ & $\begin{array}{c}\text { Examinar os } \\
\text { efeitos da co- } \\
\text { municação em } \\
\text { comparação } \\
\text { com a regra de } \\
\text { Taylor. }\end{array}$ & $\begin{array}{l}\text { Dados mensais } \\
\text { estimados por } \\
\text { OLS e Probit. }\end{array}$ & $\begin{array}{c}\text { Utiliza cin- } \\
\text { co índices } \\
\text { de outros } \\
\text { trabalhos: } \\
\text { Heinemann } \\
\text { e Ullrich } \\
\text { (2007); Ber- } \\
\text { ger, Erhmann } \\
\text { e Fratzscher. } \\
\text { (2011); Rosa } \\
\text { e Verga } \\
\text { (2007); Con- } \\
\text { rad e Lamla } \\
\text { (2007); Ullri- } \\
\text { ch (2008). }\end{array}$ & $\begin{array}{c}\text { A comunica- } \\
\text { ção é capaz } \\
\text { de afetar os } \\
\text { mercados } \\
\text { mesmo } \\
\text { controlando } \\
\text { para as in- } \\
\text { formações } \\
\text { presentes } \\
\text { na regra de } \\
\text { Taylor. }\end{array}$ \\
\hline \multicolumn{5}{|c|}{ Estudos sobre outras variáveis financeiras } \\
\hline $\begin{array}{c}\text { Gürkay- } \\
\text { nak, Sack } \\
\text { e Swanson } \\
\text { (2005) }\end{array}$ & $\begin{array}{l}\text { Analisar os efei- } \\
\text { tos da comu- } \\
\text { nicação sobre } \\
\text { o preço dos } \\
\text { ativos. }\end{array}$ & $\begin{array}{c}\text { Estudo de } \\
\text { evento em } \\
\text { dados de alta } \\
\text { frequência. }\end{array}$ & $\begin{array}{l}\text { Medido por } \\
\text { meio da } \\
\text { surpresa no } \\
\text { anúncio da } \\
\text { política mo- } \\
\text { netária. }\end{array}$ & $\begin{array}{c}\text { Tanto a } \\
\text { política } \\
\text { monetária } \\
\text { quanto a co- } \\
\text { municação } \\
\text { possuem um } \\
\text { importante } \\
\text { efeito sobre } \\
\text { o preço dos } \\
\text { ativos. }\end{array}$ \\
\hline
\end{tabular}

continua... 


\begin{tabular}{|c|c|c|c|c|}
\hline Rosa (2011) & $\begin{array}{c}\text { Analisar os } \\
\text { efeitos da co- } \\
\text { municação } \\
\text { sobre o nível e } \\
\text { a volatilidade } \\
\text { do mercado de } \\
\text { ações. }\end{array}$ & $\begin{array}{c}\text { Estudo de } \\
\text { evento em } \\
\text { dados de alta } \\
\text { frequência. }\end{array}$ & $\begin{array}{l}\text { Índice para } \\
\text { política } \\
\text { monetária } \\
\text { futura com } \\
\text { valores -1, } 0 \\
\text { e } 1 .\end{array}$ & $\begin{array}{c}\text { Tanto a } \\
\text { surpresa } \\
\text { da política } \\
\text { monetária } \\
\text { quanto os } \\
\text { comunica- } \\
\text { dos possuem } \\
\text { efeitos sobre } \\
\text { o mercado } \\
\text { de ações. }\end{array}$ \\
\hline \multicolumn{5}{|c|}{ Estudos sobre taxas de câmbio } \\
\hline $\begin{array}{c}\text { Jansen e } \\
\text { Haan (2005) }\end{array}$ & $\begin{array}{c}\text { Analisar os } \\
\text { efeitos da co- } \\
\text { municação do } \\
\text { ECB na média e } \\
\text { na variância da } \\
\text { taxa de câmbio } \\
\text { euro-dólar. }\end{array}$ & $\begin{array}{c}\text { Estudo de } \\
\text { evento em } \\
\text { dados de alta } \\
\text { frequência. }\end{array}$ & $\begin{array}{l}\text { Dummy para } \\
\text { identificar } \\
\text { quando há } \\
\text { comunicados } \\
\text { sobre a taxa } \\
\text { de câmbio. }\end{array}$ & $\begin{array}{l}\text { Os comu- } \\
\text { nicados do } \\
\text { ECB são } \\
\text { capazes de } \\
\text { influenciar a } \\
\text { volatilidade } \\
\text { da taxa de } \\
\text { câmbio. }\end{array}$ \\
\hline $\begin{array}{l}\text { Jansen } \\
\text { e Haan } \\
(2007 a)\end{array}$ & $\begin{array}{l}\text { Analisar se os } \\
\text { comunicados } \\
\text { que buscam } \\
\text { fortalecer o } \\
\text { Euro são efeti- } \\
\text { vos. }\end{array}$ & $\begin{array}{c}\text { Estudo de } \\
\text { evento em } \\
\text { dados de alta } \\
\text { frequência. }\end{array}$ & $\begin{array}{l}\text { Dummy para } \\
\text { identificar } \\
\text { quando há } \\
\text { comunicados } \\
\text { sobre a taxa } \\
\text { de câmbio. }\end{array}$ & $\begin{array}{l}\text { Os resulta- } \\
\text { dos indicam } \\
\text { que o des- } \\
\text { taque dos } \\
\text { comunica- } \\
\text { dos na mídia } \\
\text { influencia a } \\
\text { resposta dos } \\
\text { mercados. }\end{array}$ \\
\hline $\begin{array}{c}\text { Conrad } \\
\text { e Lamla } \\
(2007)\end{array}$ & $\begin{array}{l}\text { Analisar o im- } \\
\text { pacto da comu- } \\
\text { nicação do ECB } \\
\text { sobre a média } \\
\text { e a variância da } \\
\text { taxa de câmbio } \\
\text { euro-dólar. }\end{array}$ & $\begin{array}{l}\text { Estudo de } \\
\text { evento em } \\
\text { dados de alta } \\
\text { frequência } \\
\text { estimado por } \\
\text { AR-FIGARCH }\end{array}$ & $\begin{array}{l}\text { Utiliza o ECB } \\
\text { communica- } \\
\text { tor indicator, } \\
\text { que busca } \\
\text { codificar as } \\
\text { informações } \\
\text { das declara- } \\
\text { ções intro- } \\
\text { dutórias em } \\
\text { um índice } \\
\text { contínuo. }\end{array}$ & $\begin{array}{l}\text { A comuni- } \\
\text { cação do } \\
\text { banco cen- } \\
\text { tral possui } \\
\text { dois efeitos: } \\
\text { (i) justifica } \\
\text { a decisão } \\
\text { de política } \\
\text { monetária; e } \\
\text { (ii) serve de } \\
\text { guia sobre } \\
\text { a política } \\
\text { monetária } \\
\text { futura. }\end{array}$ \\
\hline
\end{tabular}

continua.. 


\begin{tabular}{|c|c|c|c|c|}
\hline $\begin{array}{c}\text { Fratzscher } \\
\text { (2008) }\end{array}$ & $\begin{array}{c}\text { Comparar os } \\
\text { efeitos de inter- } \\
\text { venções orais e } \\
\text { efetivas no mer- } \\
\text { cado de câmbio } \\
\text { euro-dólar e } \\
\text { euro-yen. }\end{array}$ & $\begin{array}{c}\text { Estudo de } \\
\text { evento em } \\
\text { dados de alta } \\
\text { frequência. }\end{array}$ & $\begin{array}{c}\text { Índice } \\
\text { para taxa } \\
\text { de câmbio } \\
\text { futura com } \\
\text { valores }-1,0 \\
\text { e } 1 .\end{array}$ & $\begin{array}{c}\text { O efeito } \\
\text { da comu- } \\
\text { nicação e } \\
\text { da política } \\
\text { monetária } \\
\text { não segue } \\
\text { a mesma } \\
\text { direção, logo } \\
\text { há evidência } \\
\text { que a comu- } \\
\text { nicação age } \\
\text { por meio do } \\
\text { canal da co- } \\
\text { ordenação. }\end{array}$ \\
\hline \multicolumn{5}{|c|}{ Estudos sobre expectativas de inflação } \\
\hline $\begin{array}{l}\text { Jansen } \\
\text { e Haan } \\
(2007 b)\end{array}$ & $\begin{array}{c}\text { Analisar o efeito } \\
\text { da comunica- } \\
\text { ção sobre as } \\
\text { expectativas } \\
\text { de inflação na } \\
\text { zona do Euro. }\end{array}$ & $\begin{array}{l}\text { Estudo de } \\
\text { evento em } \\
\text { dados de alta } \\
\text { frequência } \\
\text { estimado por } \\
\text { GARCH. }\end{array}$ & $\begin{array}{c}\text { Índice } \\
\text { baseado na } \\
\text { repetição } \\
\text { da palavra } \\
\text { "vigilante". }\end{array}$ & $\begin{array}{c}\text { Relação ne- } \\
\text { gativa entre } \\
\text { a comuni- } \\
\text { cação sobre } \\
\text { os riscos de } \\
\text { inflação e as } \\
\text { expectativas } \\
\text { de inflação } \\
\text { encontra } \\
\text { somente } \\
\text { no segundo } \\
\text { semestre de } \\
2005 . \\
\end{array}$ \\
\hline $\begin{array}{l}\text { Ullrich } \\
(2008)\end{array}$ & $\begin{array}{c}\text { Analisar o efeito } \\
\text { da comunica- } \\
\text { ção sobre as } \\
\text { expectativas } \\
\text { de inflação na } \\
\text { zona do euro. }\end{array}$ & $\begin{array}{c}\text { Dados mensais } \\
\text { estimados por } \\
\text { OLS. }\end{array}$ & $\begin{array}{l}\text { Wording indi- } \\
\text { cator: índice } \\
\text { baseado na } \\
\text { contagem } \\
\text { de palavras } \\
\text { que reflete a } \\
\text { inclinação da } \\
\text { política mo- } \\
\text { netária. }\end{array}$ & $\begin{array}{l}\text { O conteúdo } \\
\text { informacio- } \\
\text { nal sobre o } \\
\text { risco de in- } \\
\text { flação possui } \\
\text { mais influên- } \\
\text { cia sobre as } \\
\text { expectativas } \\
\text { que a tra- } \\
\text { jetória da } \\
\text { política mo- } \\
\text { netária. }\end{array}$ \\
\hline
\end{tabular}

continua... 


\begin{tabular}{|c|c|c|c|c|}
\hline \multicolumn{5}{|c|}{ Estudos para o Brasil } \\
\hline $\begin{array}{l}\text { Costa-Filho } \\
\text { e Rocha } \\
\text { (2009) }\end{array}$ & $\begin{array}{l}\text { Discutir o papel } \\
\text { da comunica- } \\
\text { ção do BCB na } \\
\text { condução polí- } \\
\text { tica monetária. }\end{array}$ & $\begin{array}{l}\text { Estudo de } \\
\text { evento em } \\
\text { dados de alta } \\
\text { frequência. }\end{array}$ & $\begin{array}{c}\text { Índice } \\
\text { baseado na } \\
\text { metodologia } \\
\text { de Rosa e } \\
\text { Verga (2007) }\end{array}$ & $\begin{array}{c}\text { Política } \\
\text { monetária } \\
\text { do BCB é } \\
\text { consistente, } \\
\text { pois as ações } \\
\text { seguem a } \\
\text { direção dos } \\
\text { comunica- } \\
\text { dos. }\end{array}$ \\
\hline $\begin{array}{c}\text { Costa Filho } \\
\text { e Rocha } \\
\text { (2010) }\end{array}$ & $\begin{array}{c}\text { Verificar se uma } \\
\text { melhor comu- } \\
\text { nicação do BCB } \\
\text { torna a política } \\
\text { monetária mais } \\
\text { previsível. }\end{array}$ & $\begin{array}{l}\text { Estudo de } \\
\text { evento em } \\
\text { dados de alta } \\
\text { frequência. }\end{array}$ & $\begin{array}{c}\text { Índice } \\
\text { baseado na } \\
\text { metodologia } \\
\text { de Rosa e } \\
\text { Verga (2007) }\end{array}$ & $\begin{array}{c}\text { Há uma ele- } \\
\text { vação das ta- } \\
\text { xas de juros } \\
\text { nos dias de } \\
\text { publicação } \\
\text { das atas com } \\
\text { redução da } \\
\text { volatilidade. }\end{array}$ \\
\hline $\begin{array}{l}\text { Mendonça e } \\
\text { Faria (2010) }\end{array}$ & $\begin{array}{c}\text { Analisar a co- } \\
\text { municação do } \\
\text { BCB, em diver- } \\
\text { sos estágios so- } \\
\text { bre a estrutura } \\
\text { a termo da taxa } \\
\text { de juros. }\end{array}$ & $\begin{array}{l}\text { Estudo de } \\
\text { evento em } \\
\text { dados de alta } \\
\text { frequência. }\end{array}$ & $\begin{array}{c}\text { Dummy para } \\
\text { identificar } \\
\text { quando há } \\
\text { comunica- } \\
\text { dos. }\end{array}$ & $\begin{array}{c}\text { Comunica- } \\
\text { ção do BCB } \\
\text { é capaz de } \\
\text { influenciar } \\
\text { as expecta- } \\
\text { tivas e mais } \\
\text { efetiva no } \\
\text { período que } \\
\text { antecede a } \\
\text { decisão so- } \\
\text { bre a política } \\
\text { monetária. }\end{array}$ \\
\hline $\begin{array}{l}\text { Montes } \\
(2012)\end{array}$ & $\begin{array}{c}\text { Analisar se há } \\
\text { resposta das } \\
\text { expectativas de } \\
\text { taxa de juros } \\
\text { em relação à } \\
\text { comunicação } \\
\text { do BCB e se a } \\
\text { direção é cor- } \\
\text { reta. }\end{array}$ & $\begin{array}{c}\text { Dados mensais } \\
\text { estimados por } \\
\text { OLS, GMM e } \\
\text { VAR. }\end{array}$ & $\begin{array}{c}\text { Índice } \\
\text { baseado na } \\
\text { metodologia } \\
\text { de Rosa e } \\
\text { Verga (2007) }\end{array}$ & $\begin{array}{c}\text { Há resposta } \\
\text { dos merca- } \\
\text { dos à co- } \\
\text { municação } \\
\text { do BCB e } \\
\text { esta se dá } \\
\text { na direção } \\
\text { esperada. }\end{array}$ \\
\hline
\end{tabular}

Fonte: Elaboração própria.

Recebido em: 08/11/2013. Aceito em: 09/03/2016. 